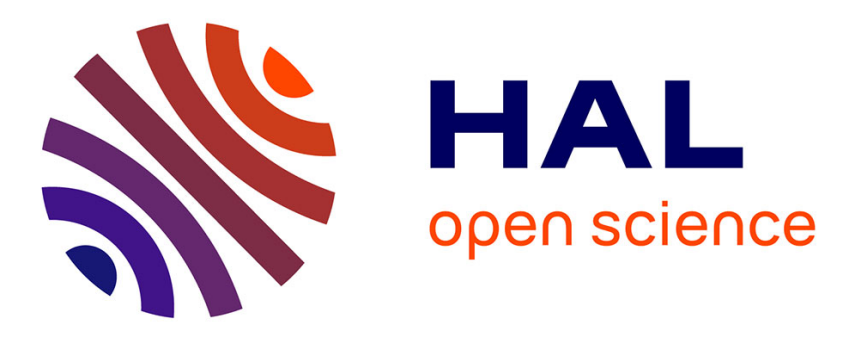

\title{
Hydraulic acclimation in a Mediterranean oak subjected to permanent throughfall exclusion results in increased stem hydraulic capacitance
}

Roberto Luis Salomón, Kathy Steppe, Jean-Marc Ourcival, Selwyn Villers, Jesús Rodríguez-Calcerrada, Roderick Schapman, Jean-marc Limousin

\section{To cite this version:}

Roberto Luis Salomón, Kathy Steppe, Jean-Marc Ourcival, Selwyn Villers, Jesús RodríguezCalcerrada, et al.. Hydraulic acclimation in a Mediterranean oak subjected to permanent throughfall exclusion results in increased stem hydraulic capacitance. Plant, Cell and Environment, 2020, 43 (6), pp.1528-1544. 10.1111/pce.13751 . hal-02997905

\section{HAL Id: hal-02997905 https://hal.science/hal-02997905}

Submitted on 17 Nov 2020

HAL is a multi-disciplinary open access archive for the deposit and dissemination of scientific research documents, whether they are published or not. The documents may come from teaching and research institutions in France or abroad, or from public or private research centers.
L'archive ouverte pluridisciplinaire HAL, est destinée au dépôt et à la diffusion de documents scientifiques de niveau recherche, publiés ou non, émanant des établissements d'enseignement et de recherche français ou étrangers, des laboratoires publics ou privés. 
4 Roberto Luis Salomón ${ }^{1}$, Kathy Steppe ${ }^{1}$, Jean Marc Ourcival ${ }^{2}$, Selwyn Villers ${ }^{1}$, Jesús Rodriguez-Calcerrada ${ }^{3}$,

5 Roderick Schapman ${ }^{1}$, Jean Marc Limousin ${ }^{2}$

6

$7 \quad{ }^{1}$ Laboratory of Plant Ecology, Department of Plants and Crops, Faculty of Bioscience Engineering, Ghent

8 University, Coupure links 653, 9000 Ghent, Belgium

$9 \quad{ }^{2}$ Centre d'Ecologie Fonctionnelle et Evolutive (CEFE), CEFE UMR 5175, CNRS, Univ Montpellier, Univ

10 Paul Valéry Montpellier 3, EPHE, IRD, 1919 route de Mende, F-34293 Montpellier, Cedex 5, France

$11{ }^{3}$ Forest Genetics and Ecophysiology Research Group, Universidad Politécnica de Madrid, Ciudad

12 Universitaria s/n 28040 Madrid, Spain

14 Running head: Stem hydraulic capacitance in a Mediterranean oak

16 Roberto Luis Salomón: RobertoLuis.SalomonMoreno@UGent.be; +32 92646114 (corresponding author)

17 Kathy Steppe: kathy.steppe@UGent.be; +32 92646112

$18 \quad J e a n$ Marc Ourcival: jean-marc.ourcival@cefe.cnrs.fr; +33 (4) 67613293

19 Selwyn Villers: selwyn.villers@UGent.be; +32 92646126

20 Jesús Rodríguez-Calcerrada: jesus.rcalcerrada@upm.es; +34 913365039

21 Roderick Schapman: schapmanroderick@hotmail.com; +32 92646126

22 Jean Marc Limousin: Jean-marc.LIMOUSIN@cefe.cnrs.fr; +33 (4) 67613293 


\section{Abstract}

25 Stem water storage capacity and hydraulic capacitance $\left(\mathrm{C}_{S}\right)$ play a crucial role in tree survival under drought26 stress. To investigate whether $\mathrm{C}_{\mathrm{S}}$ adjusts to increasing water deficit, variation in stem water content (StWC) 27 was monitored in vivo for two years and related to periodical measurements of tree water potential in 28 Mediterranean Quercus ilex trees subjected either to permanent throughfall exclusion (TE) or to control 29 conditions. Seasonal reductions in StWC were larger in TE trees relative to control ones, resulting in greater 30 seasonal $\mathrm{C}_{\mathrm{S}}\left(154\right.$ and $80 \mathrm{~kg} \mathrm{~m}^{-3} \mathrm{MPa}^{-1}$, respectively), but only during the first phase of the desorption curve, 31 when predawn water potential was above $-1.1 \mathrm{MPa}$. Below this point, $\mathrm{C}_{\mathrm{S}}$ decreased substantially and did 32 not differ between treatments $\left(<20 \mathrm{~kg} \mathrm{~m}^{-3} \mathrm{MPa}^{-1}\right)$. The allometric relationship between tree diameter and 33 sapwood area, measured via electrical resistivity tomography, was not affected by TE. Our results suggest 34 that (i) $\mathrm{C}_{\mathrm{S}}$ response to water deficit in the drought-tolerant $Q$. ilex might be more important to optimize 35 carbon gain during well-hydrated periods than to prevent drought-induced embolism formation during 36 severe drought stress, and (ii) enhanced $\mathrm{C}_{S}$ during early summer does not result from proportional increases 37 in sapwood volume, but mostly from increased elastic water.

\section{Keywords}

40 capacitive water, carbon gain optimization, desorption curve, drought-stress, electrical resistivity 41 tomography, frequency domain reflectometry, sapwood area, stem water content, rainfall exclusion, tree 42 acclimation 
44 In the early $20^{\text {th }}$ century, Spalding (1905) reported for the first time clear evidence of stem water storage

45 and related diameter changes for the Suaharo desert plant. Later studies described a significant imbalance 46 between leaf transpiration and soil water uptake, and suggested an important role of water storage 47 throughout plant tissues, mainly in the stem, to satisfy the evaporative demand under water limiting 48 conditions (Kramer, 1937, and references therein). This pioneering work demonstrated that tree stems are 49 not inert pipelines along the root-to-leaf continuum. A more recent body of studies has since highlighted

50 the physiological relevance of stem water pools in plant transpiration, hydraulic modelling and survival 51 (Waring \& Running 1978; Tyree \& Yang 1990; Goldstein et al. 1998; Zweifel et al. 2001; Steppe et al. 52 2006; Meinzer et al. 2009; Scholz et al. 2011; Salomón et al. 2017; Körner 2019; Martinez-Vilalta et al. 53 2019). These studies have helped to more comprehensively understand drought-driven embolism formation 54 and plant hydraulic functioning.

55 When a plant transpires, a gradient in water potential $(\Psi)$ along the soil-plant-atmosphere continuum is 56 generated. This vertical $\Psi$ gradient results in a radial $\Psi$ gradient between stem xylem conduits and 57 surrounding tissues that drives a dynamic radial water flow within tree stems according to transpiration needs (Steppe et al. 2015). As a result, stem water pools are depleted when the evaporative demand exceeds tree water uptake by the root system. Inversely, stem water pools are replenished when root water uptake exceeds tree transpiration until stem radial $\Psi$ gradients reach hydraulic equilibrium. Under drought stress conditions, water tension in xylem conduits increases and the xylem functionality is endangered by the risk of embolism, which may hinder tree transpiration and carbon gain. Capacitive water release from tree stems buffers increases in xylem tension thereby delaying or avoiding embolism formation in situations of water limitation (Meinzer et al. 2008, 2009; Scholz et al. 2011; Vergeynst et al. 2015). Water release from stem tissues to the transpiration stream across a gradient of xylem $\Psi$ is described by the stem desorption curve, theoretically divided into three phases (Tyree \& Yang 1990; Tyree \& Ewers 1991; Pratt \& Jacobsen 2017;

67 Steppe 2018). The first phase of this curve occurs at relatively high xylem $\Psi$, when the plant is well hydrated. 

ends), tracheids and fibres. The desorption curve flattens along the second phase as water is released at a slower rate for a comparatively large reduction in stem $\Psi$. Along this phase, water is primarily released from elastic living cells, integrating parenchyma, cambium and peridermal tissues. Finally, the desorption curve steepens during the third phase, when water is mostly released from embolized vessels or tracheids before total stem dehydration. The amount of water released at this point largely depends on the amount and lumen size of embolized conduits. Recent studies performed in vivo using X-ray microtomography question, however, whether this sequential release of capacitive water sources along the desorption curve, which has been derived from excised branches, can be extrapolated to living plants (Knipfer et al. 2017, 2019).

Stem hydraulic capacitance $\left(\mathrm{C}_{\mathrm{S}} ; \mathrm{kg} \mathrm{m}^{-3} \mathrm{MPa}^{-1}\right)$ is defined by the amount of stem water released $(\Delta \mathrm{W} ; \mathrm{kg})$ for a given change in xylem water potential $(\Delta \Psi ; \mathrm{MPa})$ per unit of tissue volume $\left(\mathrm{V} ; \mathrm{m}^{3}\right)$ (Tyree \& Ewers 1991):

$81 C_{S}=\frac{\Delta W}{\Delta \Psi} \frac{1}{V}$ Eqn. 1

82 Stem capacitance largely varies according to the stem water status (Vergeynst et al. 2015; Salomón et al. 83 2017). However, it is commonly estimated by the initial slope of the desorption curve (Meinzer et al. 2003;

84 Barnard et al. 2011; McCulloh et al. 2014; Vergeynst et al. 2015), when the stem is well hydrated. Stem 85 storage capacity is largely determined by stem size (Meinzer et al. 2004; Scholz et al. 2011), and more specifically, by sapwood volume (Goldstein et al. 1998): the larger the tree, the more room for water storage.

87 Moreover, beyond this intuitive relationship, larger trees seem to rely to a greater extent on stored water to fulfil transpiration needs (Phillips et al. 2003; Scholz et al. 2011) and thus have greater $\mathrm{C}_{\mathrm{S}}$ (Domec \&

89 Gartner 2001; McCulloh et al. 2014), although the underlying causes of a direct relation between $\mathrm{C}_{\mathrm{S}}$ and 90 sapwood volume remain unexplored. This suggests, nevertheless, that $\mathrm{C}_{\mathrm{S}}$ might be a relatively plastic trait 91 related to biomass allocation patterns: as trees grow and allocate most of their biomass to the stem (Poorter 
92 et al. 2012), the amount of conducting and storing biomass increases to the detriment of transpiring tissues

93 (i.e., leaves).

94 A trade-off between $\mathrm{C}_{\mathrm{S}}$ and xylem resistance to embolism has been reported, with "drought-avoidant" species characterized by low wood density and embolism-vulnerable xylem having large $\mathrm{C}_{\mathrm{S}}$, which dampens the reductions in xylem $\Psi$, and "drought-tolerant" species characterized by high wood density and xylem

97 conduits able to maintain functionality at low $\Psi$ having low $C_{S}$ (Meinzer et al. 2008, 2009; McCulloh et al. 2014). Accordingly, evergreen sclerophyll species across an aridity gradient exhibited lower wood density,

99 greater $C_{S}$ and less negative xylem $\Psi$ in high-rainfall sites (Richards et al. 2014). This pattern, however, does not seem to hold at the intraspecific level. Comparisons in ponderosa pine and Douglas-fir showed that, for both species, trees growing in drier locations had greater $\mathrm{C}_{\mathrm{S}}$ and sapwood thickness, and were more vulnerable to embolism formation (Barnard et al. 2011). These authors suggested that enhanced $\mathrm{C}_{\mathrm{S}}$ under drier conditions may partially explain the lack of acclimation of structural traits related to the resistance of xylem to embolism, which has been demonstrated to be limited in intraspecific comparisons across aridity gradients (Martínez-Vilalta et al. 2009; Wortemann et al. 2011; Lamy et al. 2014; Schuldt et al. 2016; Rosas et al. 2019), as well as in manipulative experiments that alter soil water availability (Limousin et al. 2010;

107 Hudson et al. 2018). On the other hand, structural adjustment of biomass allocation is a key strategy to 108 optimize water use (Magnani et al. 2002; Choat et al. 2018), and reductions of the leaf-to-sapwood area 109 ratio are commonly reported as a mechanism to maintain homeostatic minimum stem $\Psi$, and hence hydraulic 110 functionality, while supplying water to the canopy Funder drought stress (White et al. 1998; Mencuccini 111 2003; Martínez-Vilalta et al. 2009; Martin-StPaul et al. 2013; Rosas et al. 2019).

112 The need for better considering the role of stem water pools and $\mathrm{C}_{\mathrm{S}}$ in drought-driven tree mortality has 113 recently been highlighted (Körner 2019; Martinez-Vilalta et al. 2019). However, we still lack direct 114 assessments on the effect of drought stress on $\mathrm{C}_{\mathrm{S}}$ and related metrics. Permanent rainfall manipulations in 115 the field provide an excellent opportunity to investigate long-term plant acclimation to increasing water 116 limitation, as this approach allows straightforward comparison of the surveyed trait in the same species and 
117 at the same site, thus minimizing confounding co-factors that may vary over space and time. To advance

118 our knowledge on stem water pools and hydraulic acclimation to drought stress, cutting-edge technologies

119 were applied to measure in vivo stem water content (StWC), $\mathrm{C}_{\mathrm{S}}$, sap flow and sapwood area (SA) in Quercus

120 ilex trees subjected to control conditions and long-term, partial throughfall exclusion (TE) in a

121 Mediterranean stand. Variation in StWC was continuously monitored for two years using frequency domain

122 reflectometry (FDR), and SA was discretely measured applying electrical resistivity tomography. Based on

123 a previous modelling exercise at the study site, in which the reliance on stored water to daily transpiration

124 increased with drought stress (Salomón et al. 2017), and given that $\mathrm{C}_{\mathrm{S}}$ is beneficial to buffer xylem $\Psi$

125 reductions (Meinzer et al. 2009), we hypothesized that TE would enhance $\mathrm{C}_{\mathrm{S}}$, particularly under conditions

126 of severe drought stress. If true, we expected that potential increases in $\mathrm{C}_{\mathrm{S}}$ would be related to allometric

127 adjustments reflected in the relationship between stem diameter and SA.

128 Materials and methods

Site study and experiment setup

130 The study was conducted in the Puéchabon State Forest (Occitanie, France), in an experimental plot dominated by $Q$. ilex (4344029" N, 3³5045" E, 270 m.a.s.1.). The site was historically coppiced until 1942.

132 Stand density is 4700 stems ha $^{-1}$, average dominant height is $5.5 \mathrm{~m}$ and most stems (> 70\%) have a stem 133 diameter at breast height $(\mathrm{DBH})$ between 4 and $10 \mathrm{~cm}$. Climate is Mediterranean with an annual mean 134 temperature of $13.5^{\circ} \mathrm{C}$ and $953 \mathrm{~mm}$ of annual precipitation. Summer is hot and dry with less than $20 \%$ of 135 the annual precipitation falling during this season. Air temperature, precipitation and relative humidity are measured in a weather station located in the experimental site (see e.g. Rambal et al., 2014 for further details on the site). A permanent partial throughfall exclusion (TE) experiment started in spring 2003 in three plots of $10 \times 10 \mathrm{~m}$. PVC rain gutters were suspended below the canopy at $\sim 1.5 \mathrm{~m}$ above the soil in order to cover 
143 treatment located within one of the replicate plots were selected in December 2016 to measure StWC, 144 predawn and midday leaf $\Psi, \mathrm{C}_{\mathrm{S}}$ as the reduction in StWC for a given drop in $\Psi$ (see below) and stem sap 145 flow. Stem DBH of selected trees did not differ between treatments $(P=0.71)$, with mean values of 11.40 $146 \pm 0.85 \mathrm{~cm}$. Ten trees in each treatment were selected to measure SA across a wide range of stem DBH in 147 spring 2019.

Stem water content

149 Stem water content (StWC) was monitored by frequency domain reflectometry (FDR) with GS3 moisture probes (Decagon Instruments, Pullman, Wash., USA) (Hao et al. 2013; Oliva Carrasco et al. 2015; Matheny et al. 2015). According to the allometric relationship between stem diameter and SA previously observed at the experimental site (Eqn. 1 in Limousin et al., 2009), the estimated sapwood depth in monitored trees $(3.25 \pm 0.23 \mathrm{~cm})$ was smaller than the probe needle length $(5.5 \mathrm{~cm})$. Probe needles were therefore shortened to $3 \mathrm{~cm}$ with a rotary tool to avoid needle penetration into heartwood (Matheny et al., 2015). Probes were individually calibrated before installation in order to ensure the accuracy of StWC estimates from raw readings of dielectric permittivity $(\varepsilon)$. For this, $Q$. ilex trees were felled outside the experimental plots and cut into 15-cm-long stem segments of similar diameter to the selected trees. Bark was sanded in non-crooked sections before segments were immersed into deionized water overnight. Volume of stem segments was estimated the next day by Archimedes' principle to the nearest $0.1 \mathrm{~mL}$, and probes were installed afterwards. Three parallel holes were radially drilled into the stem using a customized drill guide where bark was previously sanded. To ensure a tight contact between stem and needle, the drill bit diameter was equal to that of the probe needle. A dead-blow hammer was used to carefully push the needles into the holes, and non-caustic silicone was applied to seal the stem-probe interface. After probe installation, stem segments were weighted to the nearest $0.1 \mathrm{~g}$ near water saturation point and as stems dehydrated at a room temperature of $\sim 20^{\circ} \mathrm{C}$, while $\varepsilon$ was recorded every minute with a data logger (Campbell CR3000, Campbell Scientific

166 Ltd, Shepshed, UK). Stem segments were disconnected from the logger to be weighted, twice per day during 
167 the first week of dehydration and then once per day during the second week. After two weeks, probes and

168 silicon were detached and weighted to correct weight readings of the stem segment. Dry weight was 169 determined after four additional weeks in a dry oven at $60{ }^{\circ} \mathrm{C}$ until constant weight, and $\mathrm{StWC}\left(\mathrm{kg} \mathrm{m}^{-3}\right)$ was 170 determined according to:

171 StWC $=\frac{\text { Fresh weight }- \text { Dry weight }}{\text { Volume }}$ Eqn. 2

172 The linear relationship between StWC and the mean $\sqrt{\varepsilon}$ recorded during the hour before and after the fresh 173 weight reading was established according to manufacturer indications:

$174 S t W C=a \sqrt{\varepsilon}+b$ Eqn. 3

175 where $\mathrm{a}$ and $\mathrm{b}$ are the slope and intercept of this linear relationship, respectively. A preliminary linear model 176 showed that the intercept of this relationship significantly varied with each probe $(\mathrm{P}<0.001, \mathrm{n}=9)$.

177 Considering probe as a random (intercept) factor, the slope of this relationship was significant $(\mathrm{P}<0.001)$, 178 whereas the interaction $\sqrt{\varepsilon} \times$ probe was not $(\mathrm{P}>0.1)$ denoting equal slopes among probes (Figure $\mathrm{S} 1)$. The 179 coefficient of determination of the individual fits between StWC and $\sqrt{\varepsilon}$ ranged from 0.94 to 0.99 . Given 180 the linear relationship between $\sqrt{\varepsilon}$ and StWC at any time step (Eqn. 3), the temporal (sub-daily and seasonal) 181 182 $\frac{\Delta S t W C}{\Delta t}=\frac{\Delta S t W C}{\Delta \sqrt{\varepsilon}} \frac{\Delta \sqrt{\varepsilon}}{\Delta t}=\frac{d S t W C}{d \sqrt{\varepsilon}} \frac{\Delta \sqrt{\varepsilon}}{\Delta t}=a \frac{\Delta \sqrt{\varepsilon}}{\Delta t}$ Eqn. 4

183 In this way, it is possible to determine $\Delta$ StWC rather than absolute values from $\varepsilon$ readings, thereby avoiding 184 the use of random (unknown) intercept values. After calibration, probes were installed in the field following 185 the protocol described above. Probes were installed in selected trees at approximately $0.5 \mathrm{~m}$ above the soil 186 and on the north face of the stem to avoid direct solar radiation. Readings were performed every 30 minutes 187 and recorded with a data logger (model CR1000, Campbell Scientific Ltd, Shepshed, UK). More than two years of data are shown here, from sensor installation in December 2016 (DOY 341) until DOY 365 in 2018. 

stems to evaluate the potential effect of the temperature sensitivity of $\varepsilon\left(\alpha=\Delta \varepsilon / \Delta \mathrm{T} ;{ }^{\circ} \mathrm{C}^{-1}\right)$ on estimates of

$\Delta \mathrm{StWC}$. For this, $\alpha$ was estimated on a daily basis as the slope between $\varepsilon$ and dead stem temperature $\left(\mathrm{T}_{\mathrm{STEM}}\right.$;

${ }^{\circ} \mathrm{C}$ ) recorded by the probe, and the relationship between $\alpha$ and mean daily $\varepsilon$ was evaluated across the

S2). As dead stems rehydrated during wetter months, the sub-daily relationship between $\varepsilon$ and $\mathrm{T}_{\text {STEM }}$ became

non-significant, and even inversed at the highest range of $\varepsilon(>8-9)$ resulting in negative $\alpha$ (down to -0.03

${ }^{\circ} \mathrm{C}^{-1}$ ). This variable pattern of $\alpha$ in relation to $\varepsilon$ throughout the year and the lack of overlap between $\varepsilon$ ranges

measured in dead $(\varepsilon<10)$ and living $(\varepsilon>10)$ trees prevented any temperature-correction of $\varepsilon$ to refine $\Delta$ StWC estimates.

\section{Gradients in water potential and stem water content}

To calculate gradients in $\Psi$ on seasonal and sub-daily bases, seven and six $\Psi$ measurement campaigns were performed encompassing the dry season of 2017 (DOYs 171, 185, 234, 251, 268, 284 and 298) and 2018 (DOYs 171, 187, 133, 256, 276 and 297), respectively. In each campaign, leaf $\Psi$ was measured at predawn and DOY 256 of 2018, when uniquely $\Psi_{\mathrm{PD}}$ was measured. Leaf $\Psi$ was measured with a pressure chamber (PMS1000, PMS Instruments, Corvallis, OR, USA) on freshly excised leafy shoots sampled at similar tree height and solar exposition. Two leafy shoots per tree were sampled, and a third one was added when the first two $\Psi$ readings differed by more than $0.2 \mathrm{MPa}$. In cases of missing $\Psi$ data for a particular tree at a given date ( 9 cases for a total of $104 ; 8$ trees $\times 13$ dates), treatment mean values were applied. Seasonal $\Delta \Psi$ was estimated as the reduction in $\Psi_{\mathrm{PD}}$ relative to the spring maxima (-0.45 MPa; Limousin et al., 2012). Ideally, stem $\Psi$ readings would be necessary to estimate $C_{S}$. Nevertheless, assuming hydraulic equilibrium

212 between leaf and stem $\Psi$ at predawn, the potential bias in seasonal $\mathrm{C}_{\text {s }}$ estimates is negligible. Sub-daily $\Delta \Psi$ 213 was calculated as the difference between $\Psi_{\mathrm{PD}}$ and $\Psi_{\mathrm{MD}}$ (i.e., the sap flow driving force at midday; Limousin 
214 et al., 2009). Hence, sub-daily $C_{S}$ estimates are likely underestimated as sub-daily shoot $\Delta \Psi$ can be greater 215 than that of the stem, at least during well-hydrated conditions when leaf transpiration is substantial. To 216 evaluate the potential error in sub-daily $\mathrm{C}_{\mathrm{S}}$ incurred when using shoot $\Delta \Psi$ instead of stem $\Delta \Psi$, we 217 alternatively used indirect estimates of stem $\Delta \Psi$ to estimate sub-daily $\mathrm{C}_{\mathrm{S}}$, as similarly approached in a 218 modelling exercise at this study site (Salomón et al. 2017). Briefly, leaf and stem $\Psi$ were simultaneously 219 measured at predawn and midday across a drought-stress gradient in a set of $Q$. ilex seedlings (Rodríguez220 Calcerrada et al. 2017). Stem $\Psi$ was measured by means of covering leaves with aluminium foil for $1 \mathrm{~h}$, 221 until hydraulic equilibrium was reached. The ratio between stem and leaf $\Delta \Psi$ along a gradient in $\Psi_{\mathrm{PD}}$ 222 observed in $Q$. ilex seedlings was adjusted with a sigmoidal fit and applied here to alternatively estimate 223 sub-daily $\mathrm{C}_{S}$.

224 To estimate seasonal and sub-daily $\mathrm{C}_{\mathrm{S}}$ following Eq. 1, seasonal and sub-daily $\Delta \mathrm{StWC}$ were estimated for 225 those days in which $\Psi$ measurement campaigns were performed. Seasonal $\Delta$ StWC was estimated as the 226 cumulative reduction in StWC relative to the spring maxima registered before summer drought (DOY 156 227 in 2017, and DOY 151 in 2018). Sub-daily $\Delta$ StWC was estimated as the difference between daily minimum 228 StWC registered during high-transpiration hours (from 10:00 to 19:00 h) minus daily maximum StWC 229 during low-transpiration hours (from 3:00 to 8:00 h). Additionally, the relationship between seasonal and 230 sub-daily $\triangle \mathrm{StWC}$ (not restricted to dates of $\Psi$ measurement campaigns) was evaluated across the summer 231 drought periods of 2017 and 2018. To ensure that sub-daily $\Delta \mathrm{StWC}$ was driven by transpiration, and was 232 not a consequence of water refilling following rain events, days with positive $\Delta$ StWC were excluded from 233 analyses. On average, 9\% of the days during the dry seasons in 2017 and 2018 were excluded, which is 234 lower than the number of days in which rain was registered (15\%).

236 Daily transpiration was estimated as the daily cumulative sap flow $\left(\mathrm{kg} \mathrm{day}^{-1}\right)$. Sap flow was estimated as the 237 product of sap flux density $\left(\mathrm{kg} \mathrm{cm}^{-2} \mathrm{~h}^{-1}\right)$ and sapwood area $\left(\mathrm{SA}, \mathrm{cm}^{2}\right)$. Sap flux density was measured with 238 20-mm long thermal dissipation probes designed according to Granier (1987) and installed at $1.2 \mathrm{~m}$ height. 
239 Probes were shielded with aluminium cover to avoid direct solar radiation and rainfall. Sap flux density was 240 recorded every 30 minutes with a data logger (model CR1000, Campbell Scientific) - see Limousin et al.

241 (2009) for further details. Sapwood area was estimated from stem diameter according to the allometric 242 relationship obtained for the study site (Limousin et al., 2009; see discussion). Daily release of stored water

$243\left(\mathrm{~kg} \mathrm{day}^{-1}\right)$ was estimated as the product of sub-daily $\Delta \mathrm{StWC}$ in absolute terms $\left(\mathrm{kg} \mathrm{m}^{-3}\right)$ by sapwood volume $244\left(\mathrm{~m}^{3}\right)$. Sapwood volume was estimated assuming tree cylindrical shape as the product of SA by stem height 245 measured in each tree equipped with GS3 probes. Finally, the contribution of stored water to transpiration 246 was estimated as the ratio between daily values of stored water release and transpiration.

248 Electrical resistivity tomography (ERT) was used to quantify SA in a non-destructive manner following the approach described in Benson et al. (2019). Briefly, twelve nails were inserted around each measured stem at approximately $1 \mathrm{~m}$ above the soil until the outer sapwood layer was reached. The geometry of the stem and the location of each nail was recorded using a digital calliper and a measuring tape. Nails were connected with electrodes to a 12-channel resistivity system (PiCUS TreeTronic, Argus Electronic Gmbh, Rostock, voltage application and accounting for the geometry of the stem cross section. The resulting tomogram consists of a triangular-based lattice that informs about the spatial variability in ER throughout the stem cross section. The sapwood-heartwood boundary is commonly characterized by a sharp change in water content reflected by a corresponding change in ER, and can therefore be identified as the point of steepest slope of ER along the radial profile of a tomograph (see Figure S3 for an illustration) (Guyot et al. 2013; Wang et al. 2016). To estimate SA, it is necessary to delineate the boundary between heartwood and sapwood in two dimensions at a fine spatial resolution, which is achieved by means of rotating the surveyed radial profile at a given angle (Benson et al. 2019). For this, optimal bandwidth and the order of the polynomial function (n) used for fitting the gridded data generated by ERT need to be selected a priori.

263 Here, highest $\mathrm{R}^{2}$ were obtained with a bandwidth of one $\mathrm{cm}$ and $\mathrm{n}=7$ for all surveyed trees. The $\mathrm{R}$ script 
provided as supplementary material in Benson et al. (2019) was used for SA determination. Total crosssection area derived from tape measurements (including bark) was consistently higher than that obtained via ERT $(16.4 \pm 8.6 \%)$, likely because the tip of the electrodes were located just beneath the cambium layer so the bark area was unaccounted for in the tomograms. Bark thickness was therefore set to zero in the $\mathrm{R}$ script to estimate SA from ERT. Irregularities around the perimeter of the tomography leading to equivocal detection of the sapwood-heartwood boundary were excluded from the ER radial profile. (Schapman 2019) and compare SA between treatments, ERT readings were performed around midday and alternatively between $\mathrm{C}$ and TE trees. Additionally, the accuracy of this approach was tested by examining the relationship between SA estimated via ERT and visual observation of wet sapwood depth in four freshly cut trees with similar range of DBH located outside the experimental plot (hereafter 'validation' trees). Validation trees were cut immediately after ERT readings to visually demarcate sapwood and heartwood, and SA was determined using the image-processing software ImageJ (version 1.52p, FIJI).

R software (version 3.6.1) was used for statistical analyses. Cubic smoothing splines were fitted to daily $\Delta \mathrm{StWC}$ time series to minimize noise in $\varepsilon$ readings after rain and at $\mathrm{T}_{\mathrm{STEM}}$ below $0^{\circ} \mathrm{C}$. Seasonal desorption curves exhibited a biphasic shape with different slopes at the beginning and at the end of the dry season (phases I and II hereafter). Comparisons of seasonal $\mathrm{C}_{\mathrm{S}}$ between treatments, years and between phases I and II ( $\mathrm{C}_{S_{-} I}$ and $\mathrm{C}_{S_{-} \text {II }}$ hereafter) were performed by adjusting linear segmented mixed models with the segmented.lme function (Muggeo et al. 2014). Seasonal $\Delta \mathrm{StWC}$ was determined considering treatment, year, $\Psi_{\mathrm{PD}}$ and their interaction as fixed factors, whereas tree was considered as a random slope factor. Treatment and inter-annual differences in the breakpoint along the desorption curve $\left(\Psi_{\mathrm{PD}}\right.$ separating phases I and II) and the difference-in-slope parameters (difference in slope of the desorption curve before and after the breakpoint) were also tested. Random variation in the breakpoint and the difference-in-slope parameters 
was allowed using a diagonal random effects covariance matrix. Stepwise backward selection was applied for model selection. In this model, the significance of the interaction between $\Psi_{\mathrm{PD}}$ and treatment or year denotes different slope of the desorption curve, and hence treatment or inter-annual differences in $\mathrm{C}_{\mathrm{S}}$, respectively.

293 Sub-daily $\mathrm{C}_{\mathrm{S}}$ was estimated as the ratio between sub-daily $\Delta$ StWC and $\Delta \Psi\left(\Psi_{\mathrm{PD}}-\Psi_{\mathrm{MD}}\right)$ according to Eqn.

294 1. To test the effect of $\mathrm{TE}$ and $\Psi_{\mathrm{PD}}$ on sub-daily $\mathrm{C}_{\mathrm{S}}$, linear mixed models were adjusted considering treatment, $\Psi_{\mathrm{PD}}$ and their interaction as fixed factors and tree as a random factor using the lme function. The relationship between sub-daily $\Delta \mathrm{StWC}$ and $\Delta \Psi$ was further examined by a non-linear mixed model using the nlme function, as an exponential fit reduced model residual error and AIC relative to the linear fit. The relationship between $\Psi_{\mathrm{PD}}$ and $\Delta \Psi$ was analysed likewise. To display non-linear fits, 95\% confidence intervals were estimated by first-order Taylor expansion and Monte Carlo simulation (predictNLS function in propagate library). On a daily basis, treatment differences in $\Psi_{\mathrm{PD}}$, transpiration, water storage release and the contribution of stored water to transpiration were tested with ANOVA. Because of small sample size (n $=4)$, differences with strong $(\mathrm{P}<0.05)$ and moderate $(\mathrm{P}<0.10)$ statistical significance were reported. The allometric relationship between SA and stem diameter was compared between treatments by adjusting loglog linear models and applying stepwise forward selection.

\section{Results}

The summer of 2017 was exceptionally dry, with $41.2 \mathrm{~mm}$ of rain from early June (DOY 156) to midOctober (DOY 290), when first heavy rains took place (Figure 1A). Summer drought in 2018 was less intense with $97.6 \mathrm{~mm}$ of rain from DOY 156 to 279. During these summer drought periods, mean daily air temperature ranged between 13.6 and $30.4^{\circ} \mathrm{C}$ in 2017 , and between 14.9 and $28.7^{\circ} \mathrm{C}$ in 2018 (Figure 1B). Mean daily $\mathrm{T}_{\text {STEM }}$ did not differ between treatments throughout the surveyed period, nor during 2017 or 2018 summers $(\mathrm{P}>0.78)$. The more intense summer drought in 2017 relative to 2018 was reflected by the lower yearly minimum $\Psi_{\mathrm{PD}}$ in 2017 ( $\left.\mathrm{P}<0.001\right)$. Significant differences in $\Psi_{\mathrm{PD}}$ between treatments were observed in both years $(\mathrm{P}<0.01$; Figure $1 \mathrm{C})$. Minimum $\Psi_{\mathrm{PD}}$ in 2017 was $-4.8 \pm 0.1$ and $-5.9 \pm 0.3 \mathrm{MPa}$ in 
$314 \mathrm{C}$ and TE trees, respectively, whereas minimum $\Psi_{\mathrm{PD}}$ in 2018 was $-4.2 \pm 0.1$ and $-4.6 \pm 0.1 \mathrm{MPa}$ in $\mathrm{C}$ and 315 TE trees, respectively.

317 Stem water content consistently decreased during the dry season in 2017 and 2018, reaching lowest values 318 immediately before autumn first heavy rains (Figure 1D). After 2017 autumn rains, StWC rapidly reached 319 pre-drought levels in $\mathrm{C}$ trees, whereas stem refilling was slower in TE trees and additional rain during winter 3202018 was necessary to reach pre-drought values. In 2018, stem water refilling following autumn rains was 321 similar between treatments. The larger initial seasonal decline in StWC with decreasing $\Psi_{\mathrm{PD}}$ allowed to 322 separate phases I and II of the seasonal desorption curve by their different slopes $(\mathrm{P}<0.001$, Table 1 , Figure 323 2) and hence capacitances $\left(\mathrm{C}_{\mathrm{S}_{-} \mathrm{I}}\right.$ and $\mathrm{C}_{\mathrm{S}_{-} \mathrm{II}}$, respectively). The breakpoint of the seasonal desorption curve 324 was observed at a $\Psi_{\mathrm{PD}}$ of $-0.97 \mathrm{MPa}$ and $-1.10 \mathrm{MPa}$ in 2017 and 2018, respectively, and did not differ 325 between treatments (Table 1, Figure 2). Above this $\Psi_{\mathrm{PD}}$, the interaction $\Psi_{\mathrm{PD}} \times$ treatment was significant $(\mathrm{P}$ $326<0.01$, Table 1), denoting higher $\mathrm{C}_{\mathrm{S}_{-} \mathrm{I}}$ in TE trees $\left(154 \mathrm{~kg} \mathrm{~m}^{-3} \mathrm{MPa}^{-1}\right)$ compared to $\mathrm{C}$ ones $\left(80 \mathrm{~kg} \mathrm{~m}^{-3} \mathrm{MPa}^{-}\right.$ $32{ }^{1}$ ). On the contrary, the slope of the desorption curve below the breakpoint substantially decreased (Figure 328 2), and the interaction $\Psi_{\mathrm{PD}} \times$ treatment became not significant, denoting low and similar $\mathrm{C}_{\mathrm{S}_{-} \mathrm{II}}$ between 329 treatments $\left(<20 \mathrm{~kg} \mathrm{~m}^{-3} \mathrm{MPa}^{-1}\right)$. Unexpectedly, a larger reduction in seasonal $\Delta$ StWC was observed in 2018 330 than in 2017 (Figure 1D), resulting in a significantly higher $\mathrm{C}_{\mathrm{S}_{-} \mathrm{II}}$ in 2018 relative to $2017\left(18\right.$ and $7 \mathrm{~kg} \mathrm{~m}^{-3}$ $331 \mathrm{MPa}^{-1}$, respectively; Figure 2). The interaction $\Psi_{\mathrm{PD}} \times$ treatment $\times$ year was not significant above or below 332 the breakpoint point, denoting consistency in the inter-annual treatment comparisons of both $\mathrm{C}_{\mathrm{S}_{-} \mathrm{I}}$ and $\mathrm{C}_{\mathrm{S}_{-} \mathrm{II}}$.

333 Sub-daily $\mathrm{C}_{\mathrm{S}}$ estimated using shoot $\Psi$ measurements to calculate the midday sap flow driving force $(\Delta \Psi=$ $334 \Psi_{\mathrm{PD}}-\Psi_{\mathrm{MD}}$ ) was $19.73 \pm 5.92 \mathrm{~kg} \mathrm{~m}^{-3} \mathrm{MPa}^{-1}$. When indirect estimates of stem $\Delta \Psi$ were applied (see Figure $335 \mathrm{~S} 4 \mathrm{a}$ ), sub-daily $\mathrm{C}_{\mathrm{S}}$ increased to $33.38 \pm 6.70 \mathrm{~kg} \mathrm{~m}^{-3} \mathrm{MPa}^{-1}$. Independently of the $\Delta \Psi$ applied for calculation, 336 sub-daily $\mathrm{C}_{\mathrm{S}}$ did not differ between treatments nor across a $\Psi_{\mathrm{PD}}$ gradient $(\mathrm{P}>0.1)$. Accordingly, parameters 337 of the non-linear relationship between sub-daily $\Delta$ StWC and shoot $\Delta \Psi$ did not differ between treatments 
339 (inset Figure 3), and exhibited highest values when $\Delta \Psi$ was above $2 \mathrm{MPa}$, before drought stress exacerbated.

340 Figure $\mathrm{S} 4 \mathrm{~b}$ shows these relationships when indirect estimates of stem $\Delta \Psi$ were used for calculation.

341 Seasonal and sub-daily $\Delta$ StWC were not linearly related (Figure 4A). Sub-daily $\Delta$ StWC (in absolute terms)

342 did not peak at the start of the dry season, but after mild dehydration, when the evaporative demand was

343 likely higher. Highest sub-daily $\Delta$ StWC, ranging between $25-35$ and $18-25 \mathrm{~kg} \mathrm{~m}^{-3}$, were reached in early

344 summer of 2017 and 2018, respectively (Figure 4A-B). Following seasonal dehydration, sub-daily $\Delta$ StWC

345 progressively decreased down to $5 \mathrm{~kg} \mathrm{~m}^{-3}$ for both years (Figure 4A, C-D). Overall, sub-daily $\Delta$ StWC was

346 not significantly affected by TE. Mean values of sub-daily $\Delta$ StWC were moderately higher in TE trees

347 uniquely in sparse days along phase I of the seasonal desorption curve (e.g. Figure 4B, $\mathrm{P}<0.1)$.

\section{Daily transpiration and release of stored water}

Figure 5 illustrates dynamics in transpiration, stored water release and the contribution of stored water to transpiration along the summer course, since StWC maxima until first autumn heavy rains. Transpiration maxima was close to 10 and $12 \mathrm{~kg} \mathrm{day}^{-1}$ in 2017 and 2018, respectively. Minimum transpiration rates down to $2 \mathrm{~kg} \mathrm{day}^{-1}$ were reached at the end of both dry seasons (Figure 5A-B). Release of stored water was substantially smaller, ranging from maxima of 2-3 $\mathrm{kg} \mathrm{day}^{-1}$ during spring and early summer, down to $0.2 \mathrm{~kg}$ day $^{-1}$ at the end of the dry season (Figure 5C-D). The contribution of stored water to transpiration did not exhibit any clear temporal pattern, with mean values fluctuating around 0.1 (Figure 5E-F). Transpiration tended to be higher in $\mathrm{C}$ than $\mathrm{TE}$ trees when $\Psi_{\mathrm{PD}}$ was high, although this difference was not significant (Figure 6A). Transpiration decreased with decreasing $\Psi_{\mathrm{PD}}(\mathrm{P}<0.001)$, with the interaction $\Psi_{\mathrm{PD}} \times$ treatment being significant $(\mathrm{P}<0.05)$, reflecting that $\mathrm{TE}$ trees were able to maintain similar transpiration rates at more negative $\Psi_{\mathrm{PD}}$. The release of stored water to the transpiration stream decreased with $\Psi_{\mathrm{PD}}(\mathrm{P}<0.001$; Figure 6B). It tended to be higher in TE trees, although this difference was not significant when considering the whole surveyed period; differences were uniquely observed in early summer of 2018 (Figure 5D). The daily 
tended to be higher in TE trees, differences were not significant considering the whole surveyed period and

364 were uniquely and sparsely observed during the summer of 2018 (Figure 5F).

Sapwood area

The range of electrical resistivity for each surveyed stem is displayed in Figure 7. Overall, individual ER minima and maxima largely varied independently of the treatment. Minimum ER values were mostly below $100 \Omega \mathrm{m}$, and maximum ER rarely exceeded $1600 \Omega \mathrm{m}$. The slope and intercept of the log-log linear regression between stem diameter (D) and SA did not differ between treatments $(\mathrm{P}>0.05$; Figure 8$)$. Pooling trees from $\mathrm{C}$ and TE treatments, the coefficients a and b of the allometric relationship between SA $\left(\mathrm{cm}^{2}\right)$ and $\mathrm{D}(\mathrm{cm})$ :

$372 S A=a D^{b}$ Eqn. 5

were 0.682 and 1.911 , respectively. These coefficients did not differ significantly from those previously

374 obtained at this site, in which SA area was visually determined (Limousin et al. 2009). The coefficient of 375 determination between SA estimated visually and via ERT in validation trees was 0.96, with ERT estimates 376 being higher than those visually determined (Figure S5).

\section{Discussion}

379 Methodological constrains to accurately monitor StWC in vivo have limited our knowledge about spatial 380 and temporal dynamics in $\mathrm{C}_{\mathrm{S}}$ and its response to stress elicitors, although it might be of primary relevance within the context of drought-driven tree mortality (Körner 2019; Martinez-Vilalta et al. 2019). Frequency domain reflectometry is becoming increasingly applied to the detriment of time domain reflectometry due to its comparable potential to provide continuous and long-term data on StWC in a non-destructive manner for a relatively lower cost (e.g. Hao et al., 2013; Oliva Carrasco et al., 2015; Matheny et al., 2015; Saito et 

calibration before applying parameters given by the manufacturers to estimate StWC from $\varepsilon$ readings (e.g. Hao et al., 2013; Oliva Carrasco et al., 2015). Nevertheless, these probes are originally designed and calibrated to measure soil water content and the relationship between $\sqrt{\varepsilon}$ and water content could largely differ according to the medium (Wullschleger et al. 1996; Matheny et al. 2015; Saito et al. 2016). Here, a constant slope of the relationship between $\sqrt{\varepsilon}$ and gravimetric StWC allowed reliable evaluation of $\Delta$ StWC at different timescales, but random variation of the intercept prevented the estimation of absolute StWC values. Custom probe shortening might have affected the parameters defining the $\sqrt{\varepsilon}-\mathrm{StWC}$ relationship (Matheny et al. 2015). Further calibration tests across different species and needle lengths would help to evaluate the suitability of fixed parameters given by the manufacturers to estimate StWC under different experimental conditions. Moreover, as calibration tests are, for practical reasons, generally performed during medium dehydration and not rehydration, any potential hysteretic relation between $\sqrt{\varepsilon}$ and StWC could affect the StWC readings in studies with multiple dehydration-rewetting cycles. et al. 2012). Our attempt to account for $\mathrm{T}_{\text {STEM }}$ effect on StWC estimates by means of monitoring dead trees to avoid transpiration-driven fluctuations in $\varepsilon$ did not result in a consistent relationship between $\alpha$ and $\varepsilon$ (Figure S2) that could be extrapolated to living trees. The lack of overlap between $\varepsilon$ ranges measured in dead and living trees hindered the determination of a reliable $\alpha$ that could be applied in living trees for temperature correction of $\varepsilon$ across the surveyed period, during which variation in the proportion of free and bound water possibly alters the temperature sensitivity of $\varepsilon$. Specific calibration tests applying temperature changes under controlled StWC (Saito et al. 2016) could help to reduce this potential bias in future studies.

407 Further measurement artifacts related to the wounding of stem tissues surrounding the probe needles may 408 also affect $\varepsilon$ readings. A pioneering study applying time domain reflectometry reported apparent StWC increases with time since probe installation (Wullschleger et al. 1996), which could hinder inter-annual 
411 than in 2017 was partially explained by a measurement artefact. However, inter-annual variation in $\Delta$ StWC

412 could be also be explained by different meteorological conditions. Smaller $\Delta \mathrm{StWC}$ in 2017 was caused by

413 the inter-annual difference in spring StWC maxima, which was lower in 2017 than in 2018, with the summer

414 StWC minima being similar during both years (Figure 1D). This observation could also suggest that stem

415 water reservoirs were not fully replenished in 2017 before the onset of the seasonal desorption curve.

416 Incomplete stem refilling in 2017 could be possibly attributed to relatively drier winter and spring months

417 (Figure 1A). At this time, cumulative rain previous to the spring StWC maxima in 2017 was 39, 35, 45, 53

418 and $51 \%$ of that registered in 2018 during the 1-, 2-, 3-, 4- and 5-month period preceding spring StWC 419 maxima, respectively.

\section{Seasonal and sub-daily variation in stem water content and capacitance}

421 Stem water pools were largely depleted during summer drought, as similarly observed in several species 422 subjected to water deficit (Hernández-Santana \& Martínez-Fernández 2008; Hao et al. 2013; Matheny et al.

423 2015; Beedlow et al. 2017). The seasonal desorption curve exhibited a steep decrease under well-hydrated 424 conditions, which flattened as drought-stress exacerbated. Therefore, $\mathrm{C}_{\mathrm{S}}$ decreased along the dry season, 425 with the breakpoint of the desorption curve being observed at $\Psi_{\mathrm{PD}}$ between -0.97 and $-1.10 \mathrm{MPa}$ (Figure 426 2). Capillary water is mostly released at water potentials above $-0.2 \mathrm{MPa}$ (Tyree \& Yang 1990) and largely 427 depleted below -0.5 MPa (Tyree \& Ewers 1991; Pratt \& Jacobsen 2017), which is in accordance with the 428 negative pressure required to drain capillaries as calculated from Laplace's law (Knipfer et al. 2017). 429 Therefore, capillary water might be physiologically irrelevant during phase I of the desorption curve ( $\Psi_{\mathrm{PD}}$ 430 between -0.45 and $-1.10 \mathrm{MPa}$ ) and $\mathrm{C}_{\mathrm{S}_{-} \mathrm{I}}$ could be primarily attributed to elastic living cells. The subsequent 431 reduction in $\mathrm{C}_{\mathrm{S}}$ during phase II might result from the limited contribution of largely depleted elastic pools 432 together with a small capacitive water release from vessel embolism given the remarkable embolism 433 resistance of $Q$. ilex, with $\mathrm{P}_{12}$ values down to $-4.93 \mathrm{MPa}$ (Lobo et al. 2018). Remarkably, the breakpoint of 434 the desorption curve closely matched the threshold for stem growth interruption imposed by water deficit at 435 the study site $\left(\Psi_{\mathrm{PD}}=-1.1 \mathrm{MPa}\right.$; Lempereur et al., 2015) and was not modified by TE. Stem growth being a 
436 turgor-driven process, it requires sufficient turgor pressure in the cambial cells for cell division and 437 enlargement (Hsiao \& Xu 2000; Steppe et al. 2015). Stem living cells during phase I were probably still 438 sufficiently hydrated to build-up the turgor pressure above the yield threshold, while the large depletion of 439 water pools during phase II of this curve constrained cambial turgor below this yield threshold. The 440 coincidence of these two $\Psi_{\mathrm{PD}}$ thresholds for stem growth and stem hydraulic capacitance suggests that stem 441 elastic water pools are responsible for both the stem capacitive water release along phase I and the turgor 442 pressure that drives cell wall yielding during growth.

443 Stem capacitance is commonly estimated as the initial slope of the desorption curve. Initial capacitance in 444 Q. ilex was below $160 \mathrm{~kg} \mathrm{~m}^{-3} \mathrm{MPa}^{-1}$, which is consistent with previous reports in evergreen sclerophyll 445 species (Richards et al. 2014), and is lower than the capacitance commonly observed in temperate and 446 tropical trees (Scholz et al., 2011). The shape of the seasonal desorption curve obtained here via FDR was 447 similar to that previously modelled for control trees (cf. Figure 5 in Salomón et al., 2017), using a model 448 that only accounted for the capacitive water release from outer tissues (cambium, phloem and bark). 449 Although FDR cannot discriminate between sapwood and outer tissues as water sources, it would mostly 450 reflect sapwood capacitance as most of the probe needle length $(\sim 85 \%)$ was in contact with sapwood. 451 Modelled $\mathrm{C}_{\mathrm{S}_{-} \mathrm{I}}$ of outer tissues in control trees $\left(62 \mathrm{~kg} \mathrm{~m}^{-3} \mathrm{MPa}^{-1}\right.$; Salomón et al., 2017) was lower than 452 measured $\mathrm{C}_{S_{-} \mathrm{I}}$ here $\left(80 \mathrm{~kg} \mathrm{~m}^{-3} \mathrm{MPa}^{-1}\right)$, suggesting a greater capacitance of sapwood tissues on a volume 453 basis, as similarly observed in Neotropical savanna trees (Scholz et al. 2007).

454 As initially hypothesized, permanent throughfall exclusion increased seasonal $\mathrm{C}_{\mathrm{S}}$. However, and contrary 455 to our expectations, differences were observed during phase I of the desorption curve, when trees were still 456 well-hydrated, instead of during phase II, when reliance on stored water might play a more important role 457 in maintaining xylem hydraulic functionality. These results suggest that capacitive water release to limit $\Psi$ 458 reductions represents a secondary strategy to face drought in $Q$. ilex, as this drought-tolerant species is 459 highly resistant to drought-driven embolism, with $\mathrm{P}_{50}$ values of $-7.13 \mathrm{MPa}$ (Lobo et al. 2018). Contrarily to 460 drought-avoidant species, the significance of $\mathrm{C}_{\mathrm{S}}$ in drought-tolerant species such as $Q$. ilex might be more 
461 important to maximizing carbon gain during well-hydrated conditions than to dampening $\Psi$ reductions 462 under drought stress. According to this idea, the use of stem water pools increased carbon gain by $18 \%$ in 463 Douglas-fir trees (Phillips et al. 2003) and by up to $12 \%$ in tropical forests (Bartlett et al. 2019), which can 464 be achieved by enlarging periods of transpiration at sub-daily and seasonal timescales (Goldstein et al. 1998; 465 Beedlow et al. 2017; Bartlett et al. 2019). Moreover, TE trees exhibited a more gradual decline in 466 transpiration with decreasing $\Psi_{\mathrm{PD}}$ (Figure 6A). This pattern is consistent with the reduced sensitivity of 467 transpiration to short-term fluctuations in atmospheric vapour pressure deficit (VPD) and soil moisture (SM) 468 following long-term reductions in soil water availability (Grossiord et al. 2018). Lower sensitivity of 469 transpiration to VPD and SM allows TE trees to maintain transpiration across a wider gradient of $\Psi_{\mathrm{PD}}$ but 470 comes at the cost of reduced annual tree transpiration. Transpiration of our sample of trees was $8 \%$ and $16 \%$ 471 lower in TE relative to C trees in 2017 and 2018, respectively, but a significant reduction of transpiration of 472 approximately $23 \%$ has been observed over the long-term course of the experiment and related to a reduction 473 of the trees' leaf area (Limousin et al. 2009; Gavinet et al. 2019). Reduced sensitivity of transpiration to 474 VPD can also limit water loss under conditions of very high temperature and evaporative demand, which 475 are not necessarily optimal in terms of photosynthetic carbon gain (e.g. Drake et al., 2018). Therefore, 476 although TE limits tree transpiration and carbon gain in absolute terms following leaf area reductions 477 (Limousin et al. 2009), greater $\mathrm{C}_{S_{-} \mathrm{I}}$ together with reduced sensitivity of transpiration to VPD and SM could 478 better couple transpiration dynamics with optimal photosynthetic conditions (Phillips et al. 2003), and 479 thereby improve whole-tree water use efficiency.

480 Mean sub-daily $\mathrm{C}_{\mathrm{S}}$ estimates increased from 20 to $33 \mathrm{~kg} \mathrm{~m}^{-3} \mathrm{MPa}^{-1}$ when direct shoot $\Delta \Psi$ measurements 481 and indirect estimates of stem $\Delta \Psi$ were used for calculation, respectively, thereby highlighting the need of 482 direct stem $\Psi$ measurements in future research to more accurately estimate sub-daily $\mathrm{C}_{\mathrm{S}}$. Regardless of the $483 \Delta \Psi$ used for calculation, sub-daily $\mathrm{C}_{\mathrm{S}}$ was similar between treatments and across the surveyed $\Psi_{\mathrm{PD}}$ gradient. 484 Similar sub-daily $\mathrm{C}_{S}$ concomitant with increased seasonal $\mathrm{C}_{S_{\_}}$in $\mathrm{TE}$ trees suggests that, although the 485 difference between sub-daily StWC maximum and minimum remained homeostatic between treatments, 
daily refilling along phase I of the seasonal desorption curve was more limited in TE trees (Figure 4B), eventually resulting in a greater cumulative reduction in StWC at a longer (seasonal) temporal scale. Furthermore, although the contribution of stored water to daily transpiration tended to be higher in TE, especially during the summer 2018 (Figure 5E-F), treatment differences were not significant for most of the surveyed period, as similarly observed for ponderosa pines across an aridity gradient (Maherali \& DeLucia 2001). It is important to note, however, that the small sample size in this study $(n=4)$ limits the statistical power of tests applied to detect any treatment effect. Daily stored water release and transpiration decreased proportionally with decreasing $\Psi_{\mathrm{PD}}$, resulting in a roughly constant contribution of stored water to transpiration of around 10\% (Figure 6), a value within the lower range of observations made for other species (from 10 to 50\%; reviewed by Scholz et al., 2011). A sustained contribution of sapwood water pools to daily transpiration contrasts with the modelled result that the contribution to transpiration of stored water

497 from outer tissues increased with decreasing $\Psi_{\mathrm{PD}}$ (Salomón et al. 2017). This apparently contradictory observation could be explained by the spatial location of the different water reservoirs along the stem radial profile. Sapwood water pools are intimately connected to conducting xylem vessels, possibly acting as immediate water sources to fulfil transpiration needs in a proportional manner. Contrastingly, outer tissues located over the cambium layer are indirectly connected to xylem vessels via radial ray parenchyma, possibly acting as delayed reservoirs with lower initial capacitance but able to remain hydrated for longer periods, hence increasing its contribution to transpiration as drought stress progresses.

\section{Hydraulic capacitance in relation to hydraulic allometry}

Stem water storage capacity, reliance on stored water to fulfil transpiration needs and $\mathrm{C}_{\mathrm{S}}$ are relatively 506 plastic traits related to sapwood volume and tree allometry (Scholz et al., 2011). Allometric adjustments to 507 chronic water limitation, assessed along aridity gradients, favour biomass allocation to conducting and 508 storing sapwood to the detriment of transpiring leaves (Maherali \& DeLucia 2001; Martínez-Vilalta et al. 509 2009; Martin-StPaul et al. 2013; Rosas et al. 2019). Accordingly, intra-specific comparisons in two conifer 510 species have shown greater $\mathrm{C}_{\mathrm{S}}$ in drier sites, consistent with larger sapwood thickness, number of tree rings 
511 in sapwood, percentage of tree rings in sapwood, and a (non-significant) tendency of higher sapwood 512 thickness relative to stem diameter (Barnard et al. 2011). In view of these observations, we hypothesized 513 that potential changes in $\mathrm{C}_{\mathrm{S}}$ could be attributed to a structural acclimation of the sapwood depth in response 514 to long-term water limitation. To test this hypothesis, we performed in vivo measurements of SA via ERT 515 in ten trees from each treatment. The allometric relationship between SA and stem diameter did not differ 516 between treatments (Figure 8) refuting our hypothesis. This comparison, however, should be taken with 517 caution due to unaccounted sources of variation in ER (e.g., electrolyte content, wood density; Bär et al., 518 2019), illustrated here by large differences in the ER range registered among stems (Figure 7). Unexplained 519 variability in ER may shift the point of steepest change in ER along the stem radial profile, commonly 520 resulting in overestimation of SA via ERT (Wang et al. 2016; Benson et al. 2019), as similarly observed 521 here in the four validation trees cut outside the experimental plots. Nevertheless, this bias did not 522 significantly affect the relationship between stem diameter and SA relative to that visually obtained 523 considering a larger sample size $(n=18$; Limousin et al. 2009), confirming the validity of allometric 524 extrapolations applied at the site.

525 Differences in $\mathrm{C}_{\mathrm{S}}$ were observed during phase I of the seasonal desorption curve, when elastic water pools 526 might be the largest source of capacitive water release. Regardless of similar SA between treatments, elastic 527 water pools could be larger in TE trees, as suggested by the lower wood density previously observed in 528 branches of TE trees (Limousin et al. 2010). Wood density is directly related to Young's modulus of 529 elasticity (Niklas \& Spatz 2010). Therefore, less dense wood with lower Young's modulus undergoes 530 greater elastic deformation for a given pressure, hence enabling greater release and refill of water for a given 531 change in xylem $\Psi$. This is the reason why wood density is inversely related to $\mathrm{C}_{\mathrm{S}}$ (Meinzer et al. 2009; 532 McCulloh et al. 2014). We further speculate that reductions in the leaf-to-sapwood area ratio (LA/SA) could 533 be related to the observed increase in $\mathrm{C}_{\mathrm{S}_{-} \mathrm{I}}$. Previous studies have shown that leaf biomass production in the 534 TE plot was significantly and consistently reduced by $23 \%$ (Gavinet et al., 2019) and that the leaf area 535 index was also lower because increased leaf life span or decreased leaf mass per area did not compensate 
536 for the lower leaf production (Limousin et al., 2012). Significant reductions in LA/SA were thus observed 537 at the branch level (Limousin et al. 2010a; Limousin et al., 2012) and confirmed here at the whole tree level 538 considering homeostatic SA measured via ERT and LA reductions observed in previous studies at the site.

539 The mechanism linking LA/SA ratios with $\mathrm{C}_{\mathrm{S}}$ remains, however, unclear and dedicated experiments should 540 be performed to address this hypothetical relation.

541 Further research in wood anatomy and tree water content regulation under drought stress (Knipfer et al. 542 2019; Martinez-Vilalta et al. 2019) could help to more accurately discriminate how stem capacitive water 543 sources are preferentially used during drought stress, and to better understand the underlying link between $544 \mathrm{C}_{\mathrm{S}}$ and the regulation of water potential and carbon and water exchange. More long-term data on stem water 545 pools, $\mathrm{C}_{\mathrm{S}}$ and allometric adjustments applying non-destructive techniques across different species would be 546 necessary to evaluate the generality of the pattern observed here and advance knowledge on hydraulic 547 acclimation strategies across plant functional types. Research in drought-prone Mediterranean regions could 548 be particularly informative as the largest body of research in stem water pools has so far focused on more 549 mesic (temperate and tropical) species, whose response to severe drought events could substantially differ 550 from that of drought-tolerant ones.

\section{Acknowledgements}

552 We are grateful to Karim Piquemal for assistance during calibration, installation and maintenance of GS3 553 probes, to Vito Muggeo for his valuable support on the statistical analyses of mixed segmented models, and 554 to Jonas von der Crone for his support and guidance in the analyses of ERT data. We thank two anonymous 555 reviewers for their thoughtful comments on an earlier version of this manuscript. The Puéchabon 556 experimental site belongs to the SOERE F-ORE-T, which is supported annually by Ecofor, Allenvi and the 557 French national research infrastructure ANAEE-F, and the OSU-OREME of Montpellier. This project has 558 received funding from the FWO and the European Union's Horizon 2020 research and innovation 559 programme under the Marie Skłodowska-Curie grant agreement no 665501 granted to RLS. 


\section{Conflict of Interest Statement}

561 The authors declare no conflict of interest. 


\section{References}

564 Bär A., Hamacher M., Ganthaler A., Losso A. \& Mayr S. (2019) Electrical resistivity tomography: patterns 565 in Betula pendula, Fagus sylvatica, Picea abies and Pinus sylvestris. Tree Physiology 39, 1262-1271.

566 Barnard D.M., Meinzer F.C., Lachenbruch B., McCulloh K.A., Johnson D.M. \& Woodruff D.R. (2011) 567 Climate-related trends in sapwood biophysical properties in two conifers: avoidance of hydraulic dysfunction through coordinated adjustments in xylem efficiency, safety and capacitance. Plant, Cell \& Environment 34, 643-654.

Bartlett M.K., Detto M. \& Pacala S.W. (2019) Predicting shifts in the functional composition of tropical forests under increased drought and $\mathrm{CO}_{2}$ from trade-offs among plant hydraulic traits. Ecology Letters 22, 67-77.

Beedlow P.A., Waschmann R.S., Lee E.H. \& Tingey D.T. (2017) Seasonal patterns of bole water content in old growth Douglas-fir (Pseudotsuga menziesii (Mirb.) Franco). Agricultural and Forest Meteorology 242, 109-119.

Benson A.R., Koeser A.K. \& Morgenroth J. (2019) Estimating conductive sapwood area in diffuse and ring porous trees with electronic resistance tomography. Tree Physiology 39, 484-494.

578 Chanzy A., Gaudu J.C. \& Marloie O. (2012) Correcting the temperature influence on soil capacitance 579 sensors using diurnal temperature and water content cycles. Sensors 12, 9773-9790. mortality under drought. Nature 558, 531-539. and young Douglas-fir trees. Trees 15, 204-214. 
Trees tolerate an extreme heatwave via sustained transpirational cooling and increased leaf thermal tolerance. Global Change Biology 24, 2390-2402.

Gavinet J., Ourcival J. \& Limousin J. (2019) Rainfall exclusion and thinning can alter the relationships between forest functioning and drought. New Phytologist 223, 1267-1279.

Goldstein G., Andrade J.L., Meinzer F.C., Holbrook N.M., Cavelier J., Jackson P. \& Celis A. (1998) Stem water storage and diurnal patterns of water use in tropical forest canopy trees. Plant, Cell \& Environment 21, 397-406.

Granier A. (1987) Evaluation of transpiration in a Douglas-fir stand by means of sap flow measurements. Tree Physiology 3, 309-320.

Grossiord C., Sevanto S., Limousin J.M., Meir P., Mencuccini M., Pangle R.E., .. McDowell N.G. (2018) Manipulative experiments demonstrate how long-term soil moisture changes alter controls of plant water use. Environmental and Experimental Botany 152, 19-27.

Guyot A., Ostergaard K.T., Lenkopane M., Fan J. \& Lockington D.A. (2013) Using electrical resistivity tomography to differentiate sapwood from heartwood: Application to conifers. Tree Physiology 33, 187-194.

Hao G.Y., James K.W., N. Michele Holbrook \& Guillermo Goldstein (2013) Investigating xylem embolism formation, refilling and water storage in tree trunks using frequency domain reflectometry. Journal of Experimental Botany 64, 2321-2332.

Hernández-Santana V. \& Martínez-Fernández J. (2008) TDR measurement of stem and soil water content in two Mediterranean oak species. Hydrological Sciences Journal 53, 921-931.

Hsiao T.C. \& Xu L.K. (2000) Sensitivity of with of roots versus leaves to water stress: Biophysical analysis and relation to water. Journal of Experimental Botany 51, 1595-1616. 

Impacts of long-term precipitation manipulation on hydraulic architecture and xylem anatomy of piñon and juniper in Southwest USA. Plant, Cell \& Environment 41, 421-435.

Knipfer T., Cuneo I.F., Mason Earles J., Reyes C., Brodersen C.R. \& McElrone A.J. (2017) Storage compartments for capillary water rarely refill in an intact woody plant. Plant Physiology 175, 16491660.

Knipfer T., Reyes C., Earles J.M., Berry Z.C., Johnson D., Brodersen C.R. \& McElrone A.J. (2019) Spatiotemporal coupling of vessel cavitation and discharge of stored xylem water in a tree sapling.

Körner C. (2019) No need for pipes when the well is dry-a comment on hydraulic failure in trees. Tree Plant Physiology 179, pp.01303.2018.

Kramer P.J. (1937) The relation between rate of transpiration and rate of absorption of water in plants. American Journal of Botany 24, 10-15.

Lamy J.-B., Delzon S., Bouche P.S., Alia R., Vendramin G.G., Cochard H. \& Plomion C. (2014) Limited genetic variability and phenotypic plasticity detected for cavitation resistance in a Mediterranean pine. New Phytologist 201, 874-886.

Lempereur M., Martin-StPaul N.K., Damesin C., Joffre R., Ourcival J.-M., Rocheteau A. \& Rambal S. (2015) Growth duration is a better predictor of stem increment than carbon supply in a Mediterranean

Limousin J.M., Longepierre D., Huc R. \& Rambal S. (2010) Change in hydraulic traits of Mediterranean oak forest: implications for assessing forest productivity under climate change. New Phytologist 207, 579-590. Quercus ilex subjected to long-term throughfall exclusion. Tree Physiology 30, 1026-1036. 

Hydrology 357, 57-66.

Limousin J.M., Rambal S., Ourcival J.M., Rocheteau A., Joffre R. \& Rodriguez-Cortina R. (2009) Longterm transpiration change with rainfall decline in a Mediterranean Quercus ilex forest. Global Change

Limousin J.M., Rambal S., Ourcival J.M., Rodríguez-Calcerrada J., Pérez-Ramos I.M., Rodríguez-Cortina Biology 15, 2163-2175.

Lobo A., Torres-Ruiz J.M., Burlett R., Lemaire C., Parise C., Francioni C., ... Delzon S. (2018) Assessing inter- and intraspecific variability of xylem vulnerability to embolism in oaks. Forest Ecology and

Magnani F., Grace J. \& Borghetti M. (2002) Adjustment of tree structure in response to the environment under hydraulic constraints. Functional Ecology 16, 385-393.

Maherali H. \& DeLucia E.H. (2001) Influence of climate-driven shifts in biomass allocation on water

Martin-StPaul N.K., Limousin J.-M., Vogt-Schilb H., Rodríguez-Calcerrada J., Rambal S., Longepierre D. transport and storage in ponderosa pine. Oecologia 129, 481-491.

Martínez-Vilalta J., Cochard H., Mencuccini M., Sterck F., Herrero A., Korhonen J.F.J., ... Zweifel R. (2009) Hydraulic adjustment of Scots pine across Europe. New Phytologist 184, 353-364. 
654 Matheny A.M., Bohrer G., Garrity S.R., Morin T.H., Howard C.J. \& Vogel C.S. (2015) Observations of 655 stem water storage in trees of opposing hydraulic strategies. Ecosphere 6, 165.

McCulloh K.A., Johnson D.M., Meinzer F.C. \& Woodruff D.R. (2014) The dynamic pipeline: hydraulic capacitance and xylem hydraulic safety in four tall conifer species. Plant, Cell \& Environment 37,

Meinzer F.C., James S.A. \& Goldstein G. (2004) Dynamics of transpiration, sap flow and use of stored water in tropical forest canopy trees. Tree physiology 24, 901-909.

Meinzer F.C., James S.A., Goldstein G. \& Woodruff D. (2003) Whole-tree water transport scales with sapwood capacitance in tropical forest canopy trees. Plant, Cell \& Environment 26, 1147-1155.

Meinzer F.C., Johnson D.M., Lachenbruch B., McCulloh K.A. \& Woodruff D.R. (2009) Xylem hydraulic safety margins in woody plants: coordination of stomatal control of xylem tension with hydraulic capacitance. Functional Ecology 23, 922-930.

Meinzer F.C., Woodruff D.R., Domec J.-C., Goldstein G., Campanello P.I., Gatti M.G. \& Villalobos-Vega R. (2008) Coordination of leaf and stem water transport properties in tropical forest trees. Oecologia 156, 31-41.

Mencuccini M. (2003) The ecological significance of long-distance water transport: short-term regulation, long-term acclimation and the hydraulic costs of stature across plant life forms. Plant, Cell and Environment 26, 163-182. changepoints: A maximum likelihood approach with application to treatment for depression study. Statistical Modelling 14, 293-313. 
675

676

677

678

679

680

681

682

Niklas K.J. \& Spatz H.-C. (2010) Worldwide correlations of mechanical properties and green wood density. American Journal of Botany 97, 1587-1594.

Oliva Carrasco L., Bucci S.J., Di Francescantonio D., Lezcano O.A., Campanello P.I., Scholz F.G., ... Goldstein G. (2015) Water storage dynamics in the main stem of subtropical tree species differing in wood density, growth rate and life history traits. Tree Physiology 35, 354-365.

Phillips N.G., Ryan M.G., Bond B.J., McDowell N.G., Hinckley T.M. \& Cermak J. (2003) Reliance on stored water increases with tree size in three species in the Pacific Northwest. Tree Physiology 23, 237-245.

Poorter H., Niklas K.J., Reich P.B., Oleksyn J., Poot P. \& Mommer L. (2012) Biomass allocation to leaves, stems and roots: meta-analysis of interspecific variation and environmental control. New Phytologist 193, 30-50.

Pratt R.B. \& Jacobsen A.L. (2017) Conflicting demands on angiosperm xylem: Tradeoffs among storage, transport and biomechanics. Plant Cell and Environment 40, 897-913.

Rambal S., Lempereur M., Limousin J.M., Martin-StPaul N.K., Ourcival J.M. \& Rodríguez-Calcerrada J. (2014) How drought severity constrains gross primary production (GPP) and its partitioning among carbon pools in a Quercus ilex coppice? Biogeosciences 11, 6855-6869.

Richards A.E., Wright I.J., Lenz T.I. \& Zanne A.E. (2014) Sapwood capacitance is greater in evergreen sclerophyll species growing in high compared to low-rainfall environments. Functional Ecology 28, 734-744.

Rodríguez-Calcerrada J., Jaeger C., Limousin J.M., Ourcival J.M., Joffre R. \& Rambal S. (2011) Leaf CO efflux is attenuated by acclimation of respiration to heat and drought in a Mediterranean tree. Functional Ecology 25, 983-995.

Rodríguez-Calcerrada J., Li M., López R., Cano F.J., Oleksyn J., Atkin O.K., ... Gil L. (2017) Drought- 
induced shoot dieback starts with massive root xylem embolism and variable depletion of nonstructural carbohydrates in seedlings of two tree species. New Phytologist 213, 597-610.

700

701

702

Rosas T., Mencuccini M., Barba J., Cochard H., Saura-Mas S. \& Martínez-Vilalta J. (2019) Adjustments and coordination of hydraulic, leaf and stem traits along a water availability gradient. New Phytologist 223, 632-646.

Saito T., Yasuda H., Sakurai M., Acharya K., Sueki S., Inosako K., ... Nawata H. (2016) Monitoring of stem water content of native and invasive trees in arid environments using GS3 soil moisture sensors. Vadose Zone Journal 15, 1-12.

Salomón R.L., Limousin J.-M., Ourcival J.-M., Rodríguez-Calcerrada J. \& Steppe K. (2017) Stem hydraulic capacitance decreases with drought stress: implications for modelling tree hydraulics in the Mediterranean oak Quercus ilex. Plant, Cell \& Environment 40, 1379-1391.

Schapman R. (2019) How does sapwood area measured with ERT covary with stem growth in Fagus sylvatica L.? Master thesis dissertation, Ghent Univarsity. Belgium.

Scholz F.C., Bucci S.J., Goldstein G., Meinzer F.C., Franco A.C. \& Miralles-Wilhelm F. (2007) Biophysical properties and functional significance of stem water storage tissues in Neotropical savanna trees. Plant, Cell \& Environment 30, 236-248.

Scholz F.G., Phillips N.G., Bucci S.J., Meinzer F.C. \& Goldstein G. (2011) Hydraulic Capacitance: Biophysics and Functional Significance of Internal Water Sources in Relation to Tree Size. In Sizeand Age-Related Changes in Tree Structure and Function. pp. 341-361.

Schuldt B., Knutzen F., Delzon S., Jansen S., Müller-Haubold H., Burlett R., ... Leuschner C. (2016) How adaptable is the hydraulic system of European beech in the face of climate change-related precipitation reduction? New Phytologist 210, 443-458.

Spalding E.S. (1905) Mechanical adjustment of the suaharo (Cereus giganteus) to varying quantities of 
722 Steppe K. (2018) The potential of the tree water potential. Tree Physiology 38, 937-940.

723 Steppe K., De Pauw D.J.W., Lemeur R. \& Vanrolleghem A. (2006) A mathematical model linking tree sap 724 flow dynamics to daily stem diameter fluctuations and radial stem growth. Tree Physiology 26, 257$725 \quad 273$.

726 Steppe K., Sterck F. \& Deslauriers A. (2015) Diel growth dynamics in tree stems: linking anatomy and ecophysiology. Trends in Plant Science 20, 335-343.

Tyree M. \& Ewers F.W. (1991) The hydraulic architecture of trees and other woody plants. New Phytologist 119, 345-360.

Tyree M.T. \& Yang S. (1990) Water-storage capacity of Thuja, Tsuga and Acer stems measured by dehydration isotherms. Planta 182, 420-426.

Vergeynst L.L., Dierick M., Bogaerts J.A.N., Cnudde V. \& Steppe K. (2015) Cavitation: A blessing in disguise? New method to establish vulnerability curves and assess hydraulic capacitance of woody tissues. Tree Physiology 35, 400-409.

Wang H., Guan H., Guyot A., Simmons C.T. \& Lockington D.A. (2016) Quantifying sapwood width for three Australian native species using electrical resistivity tomography. Ecohydrology 9, 83-92.

Waring R.H. \& Running S.W. (1978) Sapwood water storage: its contribution to transpiration and effect upon water conductance through the stems of old-growth Douglas-fir. Plant, Cell and Environment 1,

White D., Beadle C., Worledge D., Honeysett J. \& Cherry M. (1998) The influence of drought on the relationship between leaf and conducting sapwood area in. Trees 12, 406. 
743 Genotypic variability and phenotypic plasticity of cavitation resistance in Fagus sylvatica L. across $744 \quad$ Europe. Tree Physiology 31, 1175-1182.

745 Wullschleger S.D., Hanson P.J. \& Todd D.E. (1996) Measuring stem water content in four deciduous 746 hardwoods with a time- domain reflectometer. Tree Physiology 16, 809-815.

747 Zweifel R., Item H. \& Häsler R. (2001) Link between diurnal stem radius changes and tree water relations.

$748 \quad$ Tree physiology 21, 869-877.

749 
750 Table 1. Fixed effects of the segmented mixed linear model for the seasonal relationship between predawn 751 water potential $\left(\Psi_{\mathrm{PD}}\right)$ and the reduction in stem water content relative to the spring maxima $(\Delta \mathrm{StWC})$ in 752 trees subjected to throughfall exclusion (TE) and control conditions across two consecutive years (2017 and 753 2018).

\begin{tabular}{|c|c|c|c|}
\hline & Value & SE & $\mathrm{P}-\mathrm{v} / 28 \mathrm{Ae}$ \\
\hline Intercept & -35.79 & 8.27 & $\begin{array}{c}0.0000 \\
755\end{array}$ \\
\hline Treatment (TE) & -43.24 & 10.01 & 0.0050 \\
\hline Left slope & & & 756 \\
\hline$\Psi_{\mathrm{PD}}$ & 7.28 & 3.21 & 0.0251 \\
\hline$\Psi_{\mathrm{PD}} \times$ Year $(2018)$ & 10.41 & 1.46 & $\begin{array}{c}0.0000 \\
758\end{array}$ \\
\hline Slope change (U) & & & \\
\hline $\mathrm{U}$ & 67.98 & 17.64 & 0.06592 \\
\hline $\mathrm{U} \times$ Treatment $(\mathrm{TE})$ & 73.44 & 24.63 & 0.09360 \\
\hline \multicolumn{4}{|l|}{ Breakpoint $\left(\mathrm{G}_{0}\right)$} \\
\hline$\overline{\mathrm{G}_{0}}$ & -0.97 & 0.09 & 761 \\
\hline $\mathrm{G}_{0} \times$ Year $(2018)$ & -0.13 & 0.06 & $0.0 \overline{355}$ \\
\hline
\end{tabular}

763 Significant $\Psi_{\mathrm{PD}} \times$ Year interaction indicates different slope of the relationship between $\Psi_{\mathrm{PD}}$ and $\Delta \mathrm{StWC}$ at 764 the left-hand side of the breakpoint in Figure 2, and therefore different stem capacitance between years 765 during phase II of the desorption curve $\left(\mathrm{C}_{S_{-} \mathrm{II}}\right)$. Significant $\mathrm{U}$ indicates significant change in slope at the 766 breakpoint (difference in slope of the desorption curve before and after the breakpoint), so that $\mathrm{C}_{S_{-} I}$ is higher 767 than $\mathrm{C}_{\text {S_II. }}$ Significant $\mathrm{U} \times$ Treatment interaction indicates different change in the slope between treatments 768 at the right-hand side of the breakpoint in Figure 2, and therefore higher $\mathrm{C}_{\mathrm{S}_{-} \mathrm{I}}$ in TE trees. The breakpoint $\mathrm{G}_{0}$ 769 differed between years. The standard deviation of the random effects considering a diagonal random effects 770 covariance matrix was 7.470, 0.310, 0.002 and 19.71 for $\Psi_{\mathrm{PD}}, \mathrm{U}, \mathrm{G}_{0}$ and the residual, respectively. 
771 Figure 1. Daily values of precipitation (A), mean daily temperature (B), leaf water potential ( $\Psi$ ) at predawn 772 and midday $(C)$, and variation in stem water content $(\triangle \mathrm{StWC} ; \mathrm{D})$ since sensor installation in four trees 773 subjected to throughfall exclusion (TE) and control (C) treatment conditions.

774 Mean values \pm SE per treatment $(n=4)$ are shown. Treatment differences in predawn $\Psi$ are shown by 775 asterisks $(\mathrm{P}<0.05)$.

776 Figure 2. Seasonal relationship between predawn water potential $\left(\Psi_{\mathrm{PD}}\right)$ and the cumulative reduction in 777 stem water content $(\triangle \mathrm{StWC})$ during summer drought relative to the spring maxima measured in trees 778 subjected to throughfall exclusion (TE) and control (C) conditions during two consecutive summers.

779 Points illustrate mean values \pm SE per treatment $(n=4)$ and measurement campaign. Seasonal desorption 780 curves were adjusted with segmented mixed models. The slopes of these curves above and below the 781 breakpoint equal stem hydraulic capacitance during the first and second phase of the seasonal desorption 782 curve, respectively.

783 Figure 3. Relationship between midday sap flow driving force (difference between predawn and midday 784 shoot water potential, $\left.\Delta \Psi=\Psi_{\mathrm{PD}}-\Psi_{\mathrm{MD}}\right)$ and sub-daily variation in stem water content $(\Delta \mathrm{StWC})$. The inset 785 illustrates the relationship between $\Delta \Psi$ and $\Psi_{\mathrm{PD}}$. Measurements were performed in trees subjected to 786 throughfall exclusion (TE) and control (C) conditions during two consecutive summers.

787 Points illustrate mean values \pm SE per treatment $(n=4)$ and measurement campaign. Fit displayed was 788 adjusted with a non-linear model pooling data from different treatments and years.

789 Figure 4. Relationship between seasonal (cumulative) and sub-daily variation in stem water content 790 ( $\triangle$ StWC) during two consecutive summers in trees subjected to throughfall exclusion (TE) and control (C) 791 conditions (A). Three representative 48-h periods across the 2017 seasonal desorption curve were selected 792 to illustrate sub-daily $\Delta$ StWC at an hourly temporal resolution (B-D).

793 Mean values per treatment $(n=4)$ and the smooth curve adjusted by local polynomial regression with its 
95\% confidence intervals are shown. Solid and dashed lines represent 2017 and 2018 fits, respectively (A). Sub-daily $\triangle$ StWC was moderately $(\mathrm{P}<0.1)$ higher in $\mathrm{TE}$ trees at the seasonal spring maximum $(\mathrm{B})$, whereas differences became non-significant at the breakpoint of the seasonal desorption curve (C), and at the end of the dry season immediately before first autumn rain (D).

798 Figure 5. Daily values of transpiration (A-B), release of stored water (C-D) and the contribution of stored water to transpiration (E-F) in trees subjected to throughfall exclusion (TE) and control (C) conditions during two consecutive summers (2017 and 2018).

801 Mean values \pm SE per treatment $(n=4)$ are shown. Treatment differences at $\alpha$ level of 0.05 and 0.1 are 802 shown by asterisks and points, respectively.

803 Figure 6. Relationships between predawn water potential ( $\left.\Psi_{\mathrm{PD}}\right)$ and daily transpiration $(\mathrm{A})$, stored water 804 release (B), and the contribution of stored water to transpiration (C). Data were obtained from trees subjected 805 to throughfall exclusion (TE) and control (C) conditions during two consecutive summers.

806 Mean values \pm SE per treatment $(n=4)$ and measurement campaign are shown. Regression lines shown 807 when the relationship with $\Psi_{\mathrm{P}}$ was significant $(\mathrm{P}<0.05)$. Different lines per treatment shown when the 808 interaction $\Psi_{\mathrm{PD}} \times$ treatment was significant.

809 Figure 7. Electrical resistivity tomographies of ten trees subjected to control conditions (left panel) and 810 permanent throughfall exclusion (right panel).

811 Horizontal and vertical axes in each tomograph illustrate the dimension of the stem cross-section in $\mathrm{m}$. The 812 range of electrical resistivity $(\mathrm{ER}, \Omega \mathrm{m})$ is depicted by the colour bar. In some cases, irregularities around 813 the perimeter of the cross section resulted in high ER. These irregularities were excluded from the ER radial 814 profile to locate the heartwood-sapwood boundary. Note that images directly generated by the PICUS 815 software do not illustrate the actual range of ER values, but maximize the colour contrast towards the centre 816 of the tomography by adjusting the range of the colour map. 
817 Figure 8. Relationship between stem diameter and sapwood area measured via electrical resistivity 818 tomography in trees subjected to throughfall exclusion (TE) and control (C) conditions.

819 Solid lines and polygons represent the mean \pm SE of the exponential fits. Black points display the diameter820 sapwood area relationship previously observed at the site (Limousin et al. 2009) for comparison purposes.

821 Figure S1. Calibration of GS3 probes to estimate stem water content (StWC) from raw readings of dielectric 822 permittivity $(\varepsilon)$.

823 Figure S2. Relationship between mean daily dielectric permittivity $(\varepsilon)$ and temperature sensitivity of $\varepsilon(\alpha)$ 824 across the surveyed period.

825 Figure S3. Electrical resistivity (ER) along a radial profile of a cross section of a Quercus ilex stem segment 826 used to determine the boundary between sapwood and heartwood.

827 Figure S4. Ratio between stem and leaf $\Delta \Psi$ along a gradient in $\Psi_{\mathrm{PD}}$ observed in a different set of $Q$. ilex 828 seedlings (A), and the resulting relationship between sub-daily variation in stem water potential (difference 829 between predawn and midday stem water potential, $\Delta \Psi=\Psi_{\mathrm{PD}}-\Psi_{\mathrm{MD}}$ ) and sub-daily variation in stem water 830 content $(\Delta \mathrm{StWC})(\mathrm{B})$.

831 Figure S5. Linear relationship between sapwood area (SA) estimates obtained visually and via electrical 832 resistivity topography (ERT).

833 
Figure 1
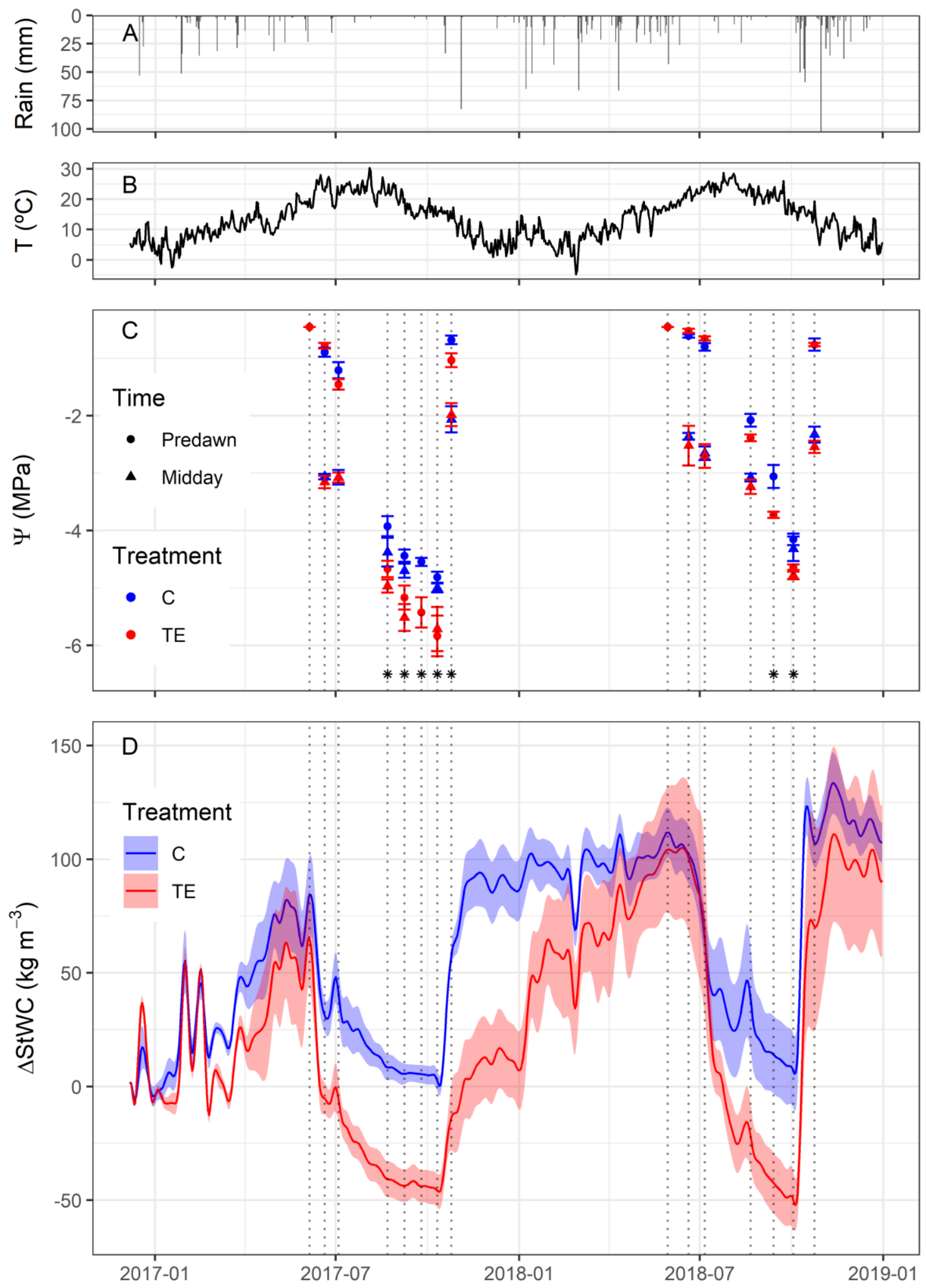
Figure 2

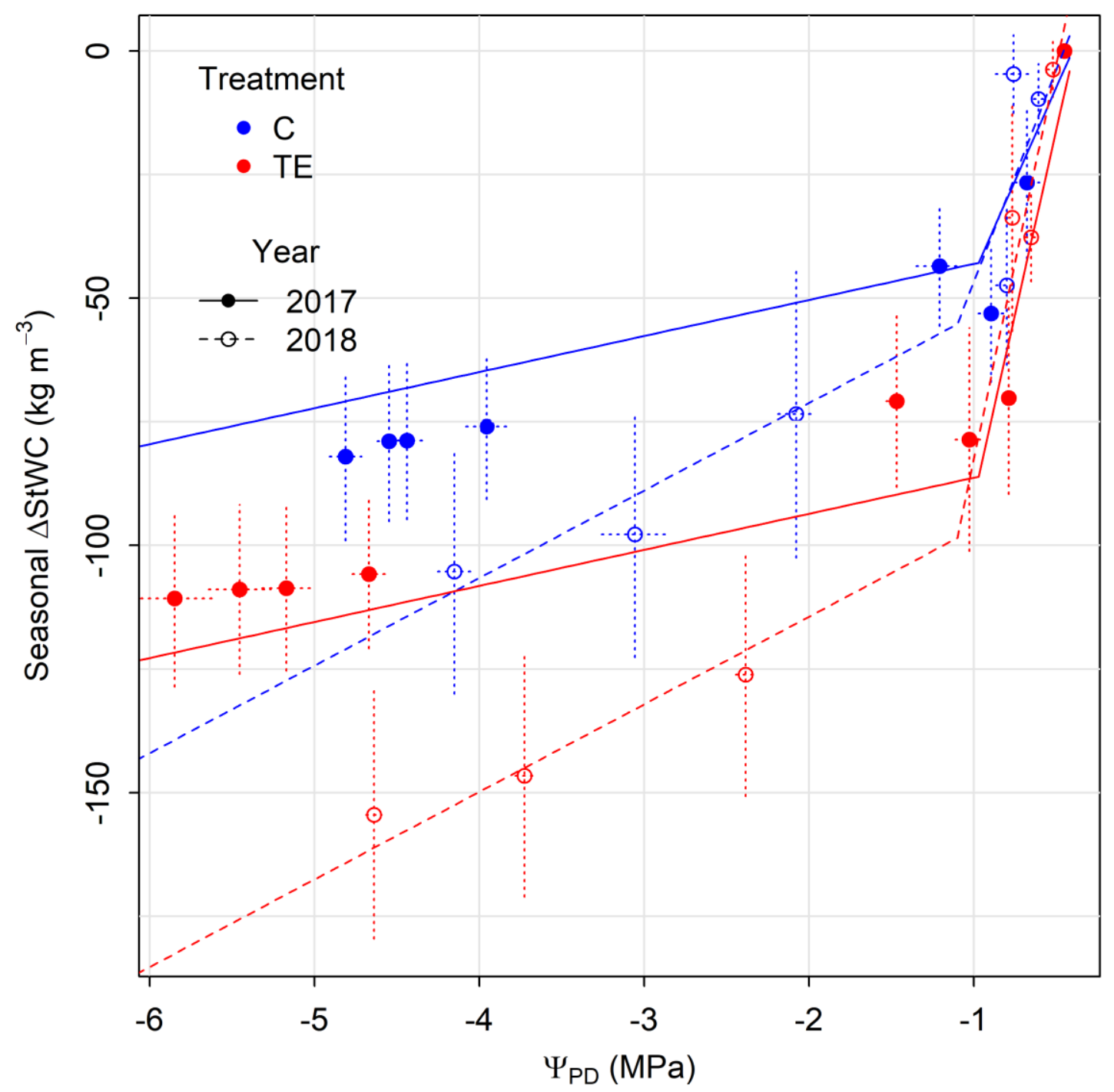

837 
Figure 3

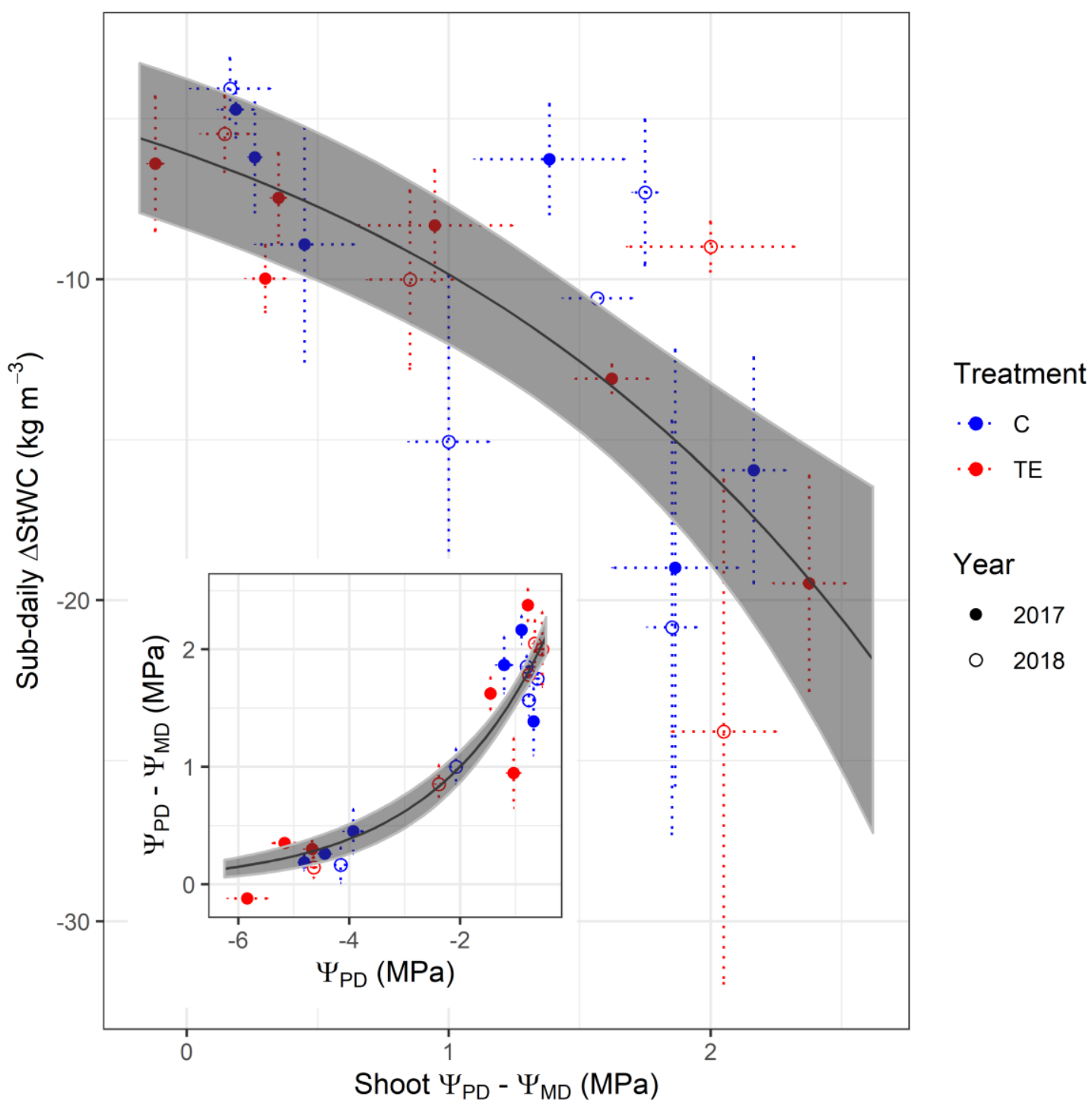

840 

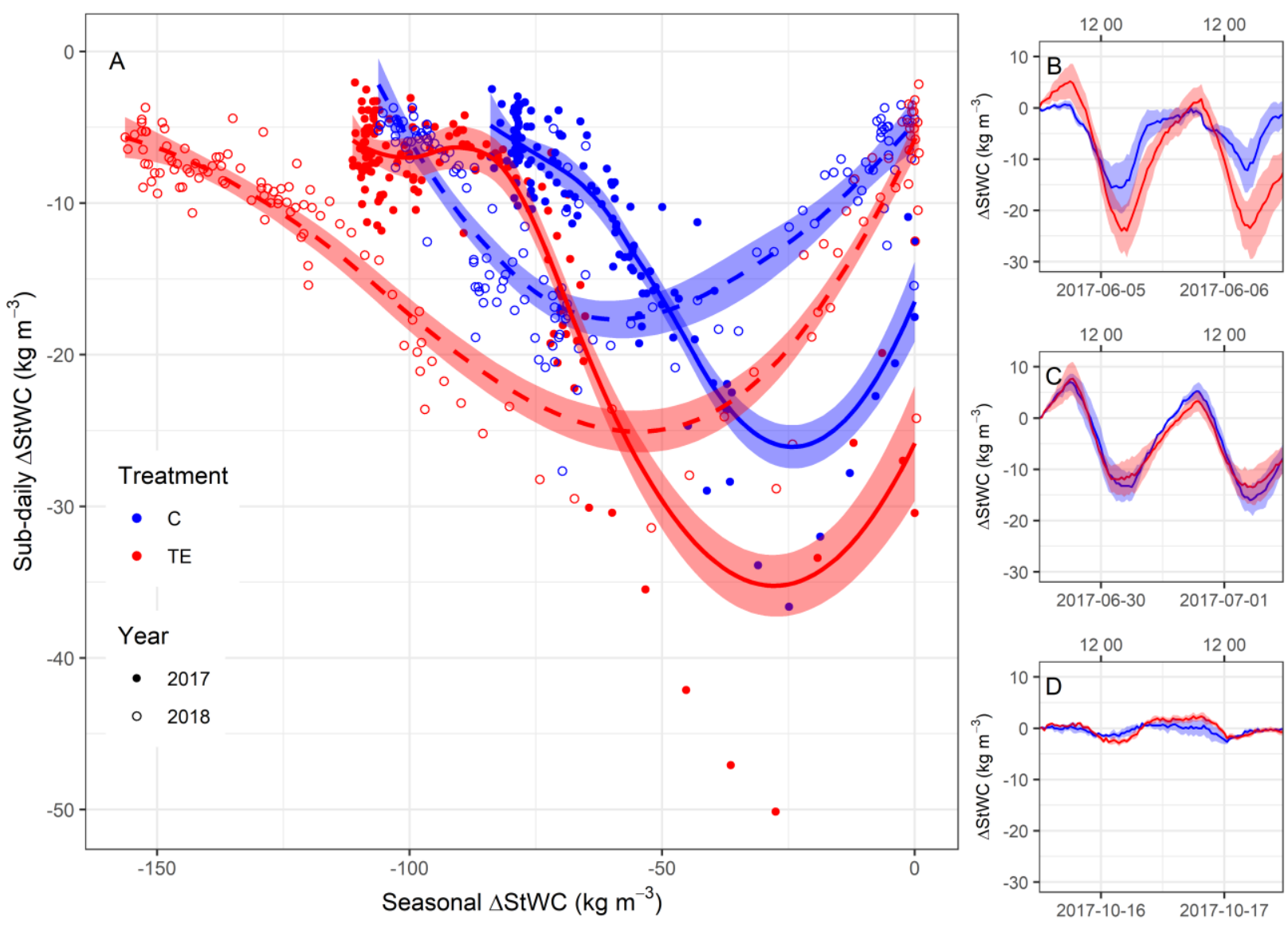

843 
Figure 5
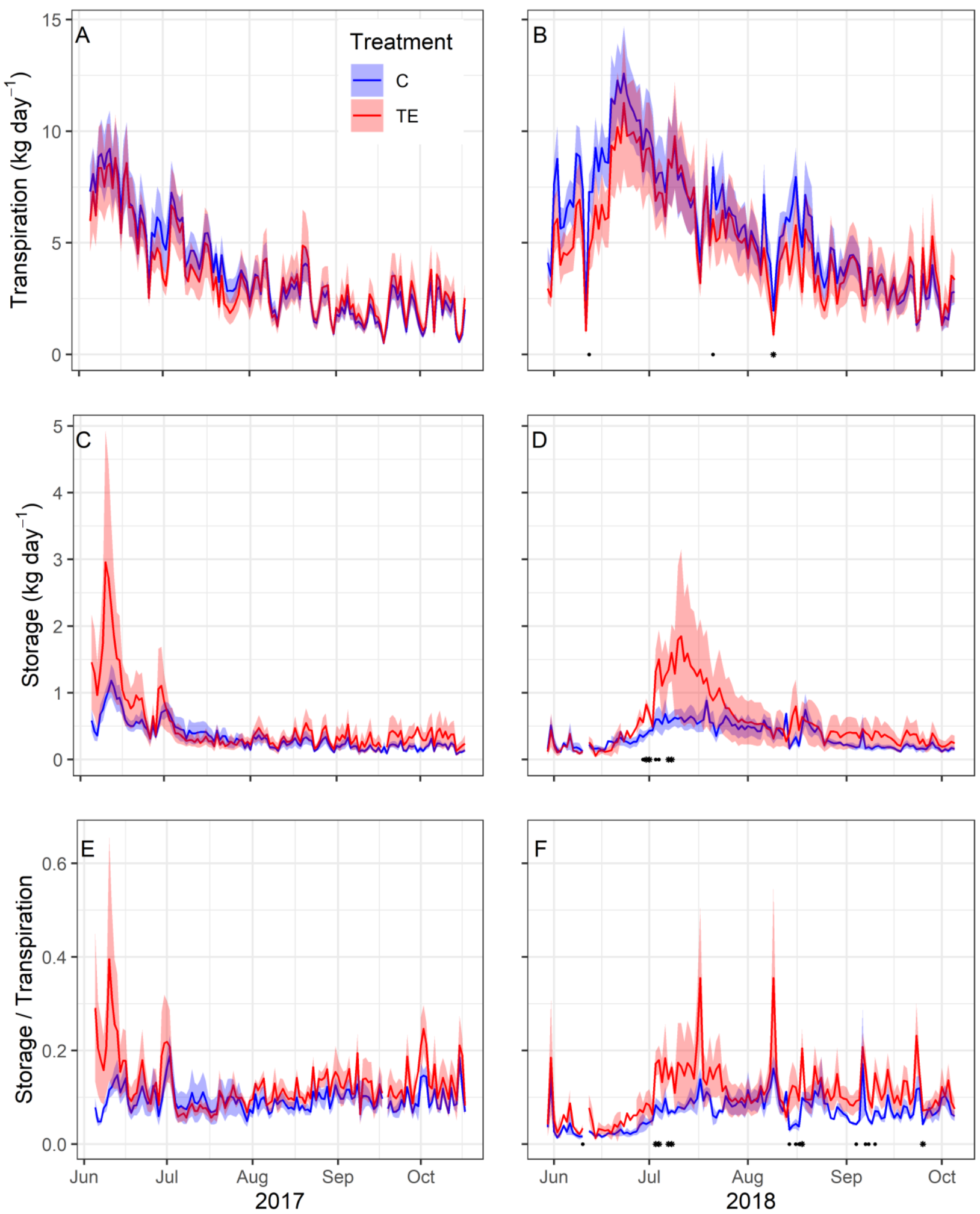
Figure 6
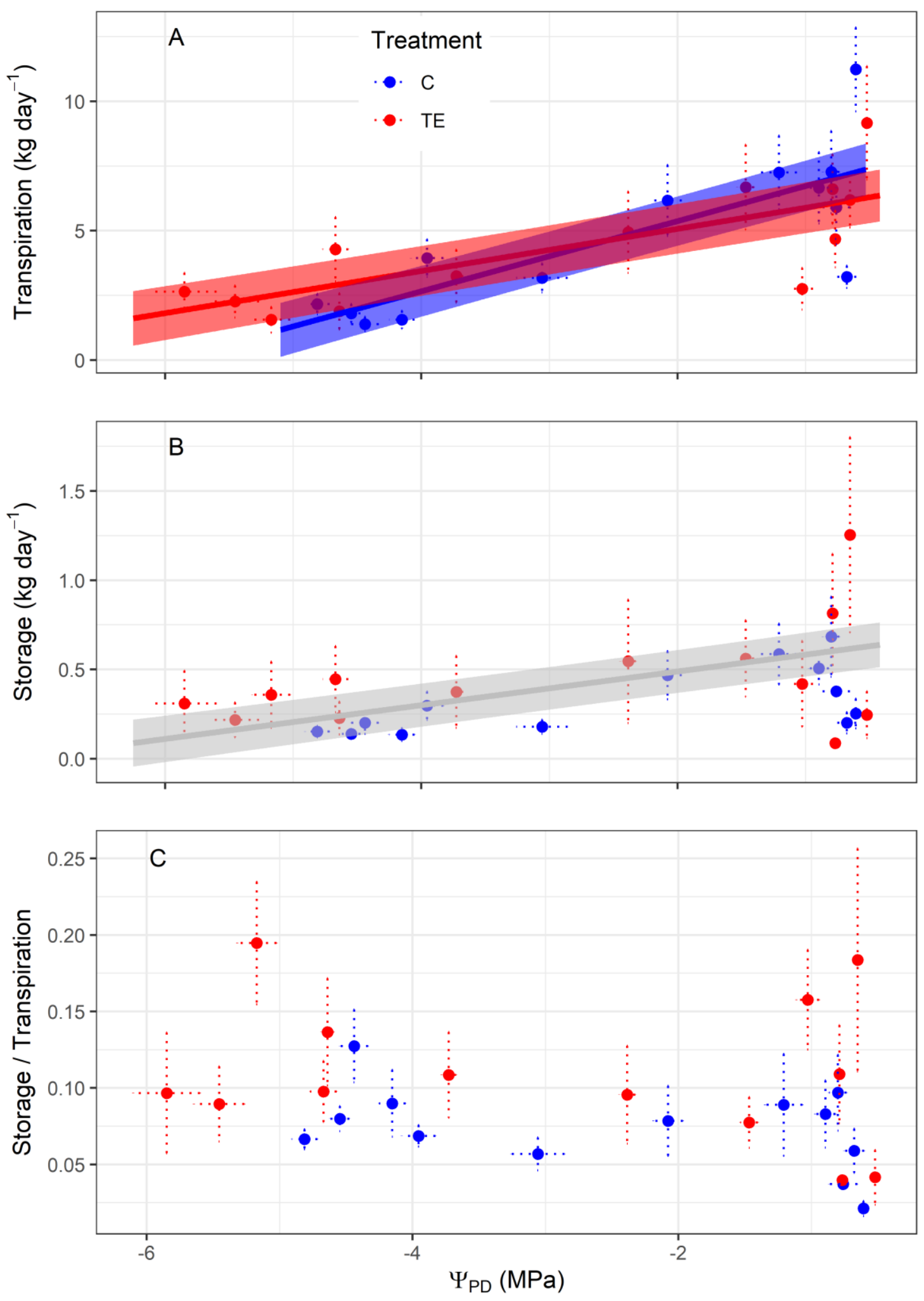

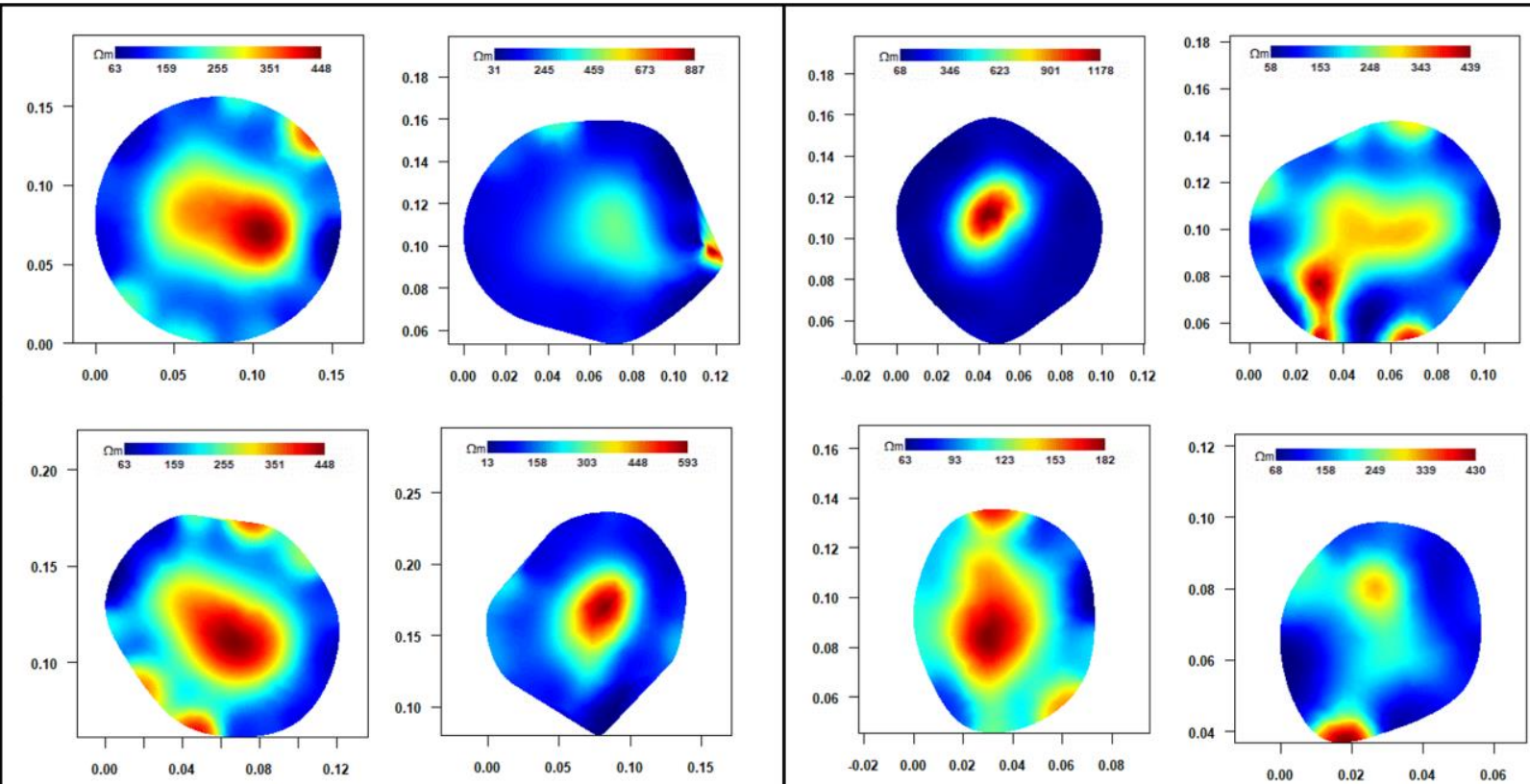

$\begin{array}{llllll}0.00 & 0.02 & 0.04 & 0.06 & 0.08 & 0.10\end{array}$
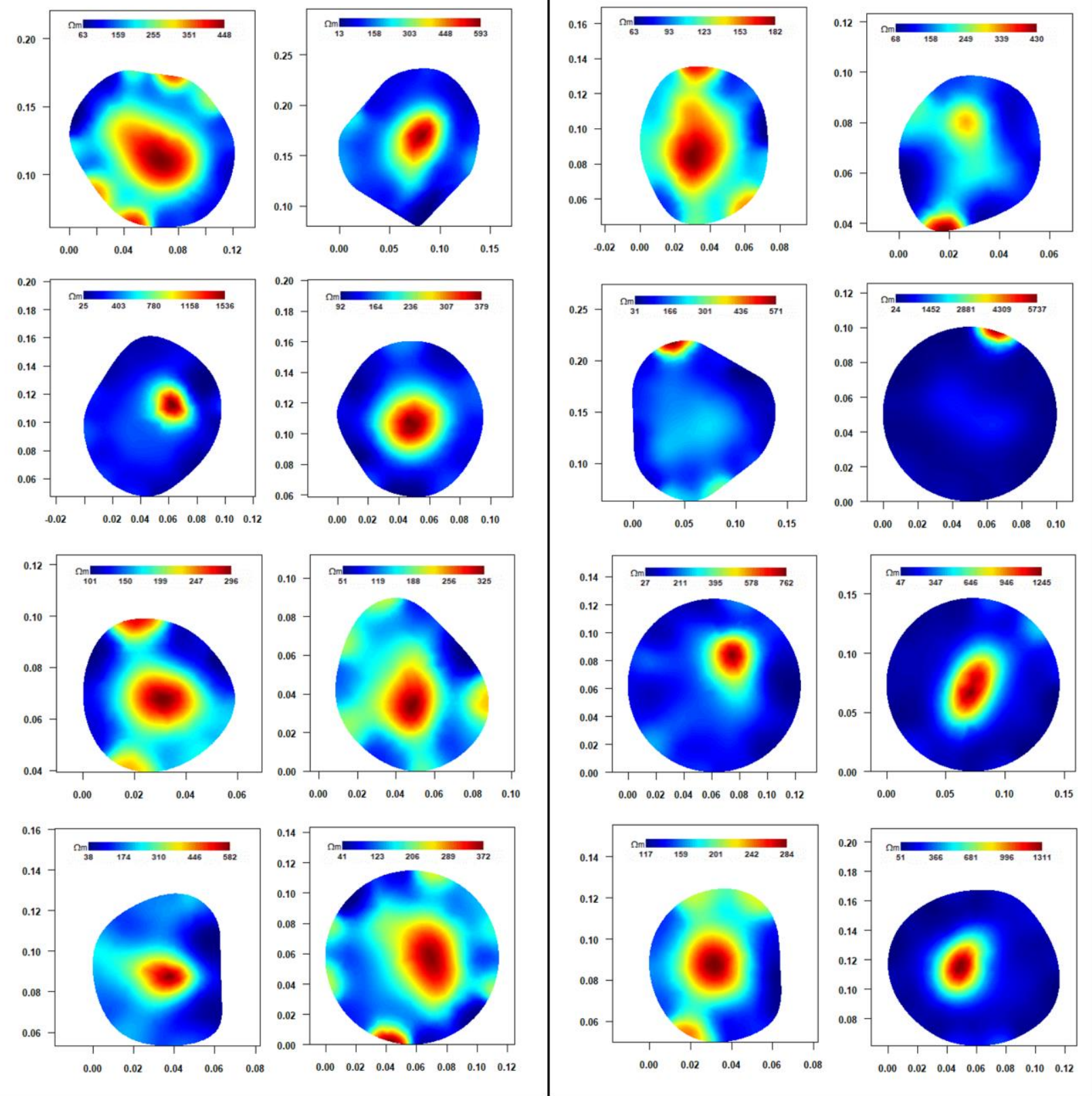
851 Figure 8

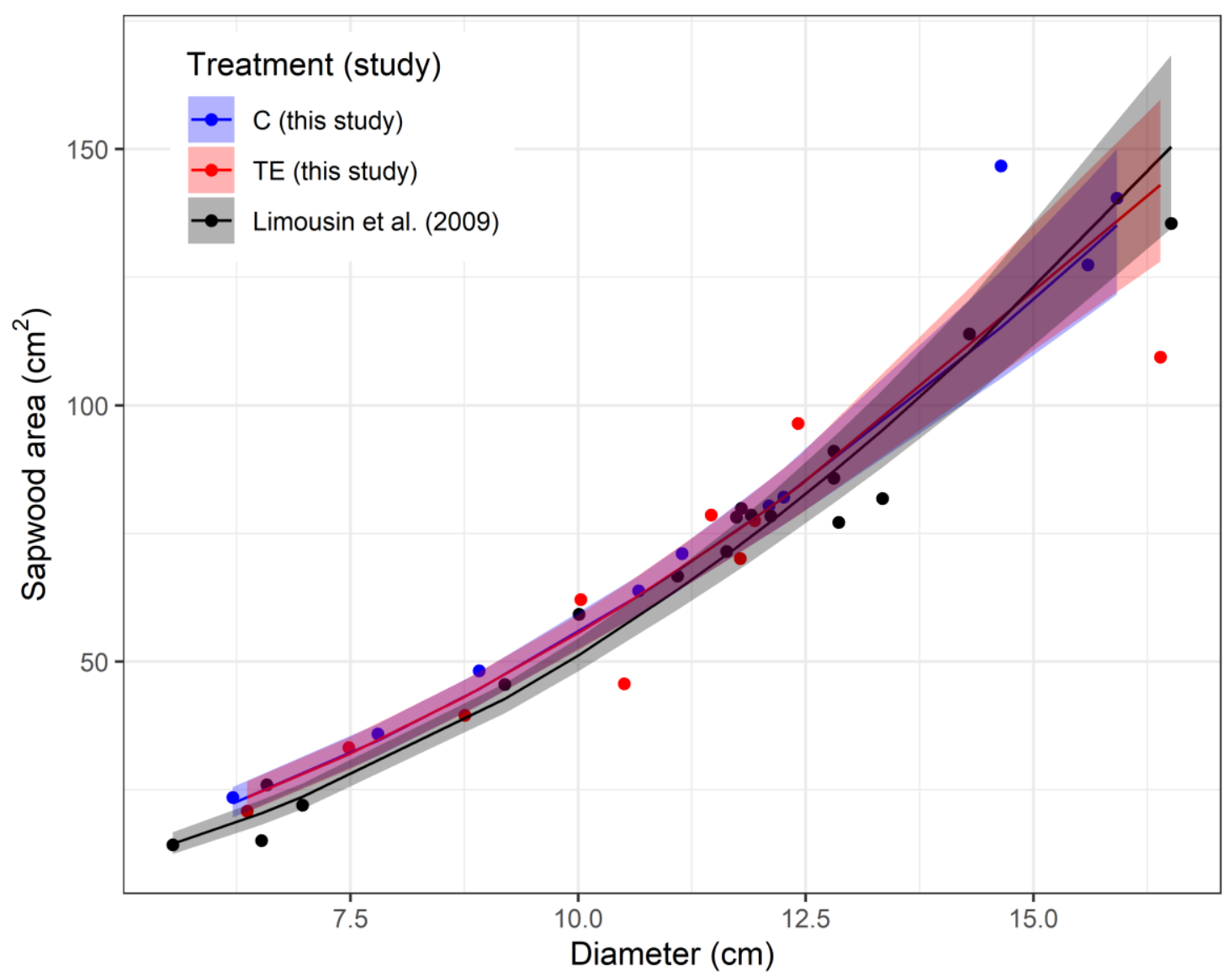

852 